\title{
Iodine Hall-Effect Electric Propulsion System Research, Development, and System Durability Demonstration
}

\author{
Gabriel F. Benavides, ${ }^{1}$ Hani Kamhawi², Jonathan A. Mackey ${ }^{3}$, and Thomas W. Haag ${ }^{4}$ \\ NASA Glenn Research Center, Cleveland, OH, 44135, USA \\ and \\ Gustavo C. C. Costa ${ }^{5}$ \\ Vantage Partners, LLC, Cleveland, OH, 44135, USA
}

\begin{abstract}
This paper reviews recent iodine electric propulsion research and development activities at the NASA Glenn Research Center (GRC). Activities included (i) investigation of the iodine compatibility of $\mathrm{BaO}-\mathrm{CaO}-\mathrm{Al}_{2} \mathrm{O}_{3}$ impregnated tungsten hollow cathodes based on a flight heritage design, (ii) investigation of the iodine compatibility of a handful of materials common to propulsion systems, spacecraft, and ground test facilities, (iii) development of reliable iodine feed system technologies, (iv) implementation of test facility improvements in an attempt to mitigate iodine associated negative impacts, and culminated in (v) an 1,174-hour hybrid iodine-xenon propulsion system durability demonstration (iodine fed Hall-effect thruster with xenon fed cathode). Each of the activities resulted in extensive insights that shall inform future iodine electric propulsion developments. While reliable operation of a $\mathrm{BaO}-\mathrm{CaO}-\mathrm{Al}_{2} \mathrm{O}_{3}$ impregnated tungsten hollow cathode on iodine vapor was not achieved, long-term operation on xenon gas in proximity to an iodine fed thruster was demonstrated without any measurable degradation or cross-contamination of the cathode. Furthermore, iodine material corrosion investigations conducted at $300^{\circ} \mathrm{C}$ over 5,15 , and 30 days showed significant deterioration of all materials evaluated, although the same materials with a silicon coating proved nearly impervious to iodine so long as the coating was not mechanically damaged. Finally, the 1,174hour durability test demonstration showed that (i) iodine feed system technologies developed at GRC delivered well-regulated uninterrupted propellant, (ii) implementation of appropriate facility improvements and procedures can limit negative impacts of iodine on test hardware and ground support equipment, although facility challenges with iodine are extensive, and (iii) a Hall-effect thruster operates with similar performance whether employing iodine or xenon propellant over long durations. The work was motivated by strong government and commercial interest in the growing capabilities of small-spacecraft $(<500 \mathrm{~kg})$, in combination with interest for denser low-power, high delta-v in-space propulsion systems. This work adds to a growing body of research and development efforts aimed at addressing the many anticipated challenges of implementing iodine as an in-space propellant. This work was conducted under the Advanced In-Space Propulsion (AISP) project funded through the Game Changing Development (GCD) program within NASA's Science Technology Mission Directorate (STMD).
\end{abstract}

\section{Introduction}

Since the 1960s, there have been periodic efforts to institutionalize within NASA an exploration and science mission approach of smaller, faster, and cheaper spacecraft [1]. Smaller spacecraft offer NASA many expected advantages, including reduced development time, lower launch cost, and generally an ability to accept greater risk. Conversely, the drawback of smaller spacecraft is the inability to carry the same diversity of scientific payloads as

\footnotetext{
${ }^{1}$ Research Engineer, Electric Propulsion Systems Branch, AIAA Senior Member.

2 Senior Research Engineer, Electric Propulsion Systems Branch, AIAA Associate Fellow.

${ }^{3}$ Research Engineer, Electric Propulsion Systems Branch, AIAA Member.

${ }^{4}$ Senior Research Engineer, Electric Propulsion Systems Branch, AIAA Senior Member.

${ }^{5}$ Project Scientist, Environmental Effects \& Coatings Branch, AIAA Non-Member.
} 
larger spacecraft. One logical compromise is employing multiple smaller spacecraft with similar, but distributed, capability to a large spacecraft. With multiple smaller spacecraft, loss of any single spacecraft permits continuation of the mission, but with only a partial reduction in capability. On the other hand, system failures on a single large spacecraft can effectively end a mission. Recent advances in launch vehicle and spacecraft technologies make now an especially opportune time to further pursue harnessing small spacecraft for NASA missions. A few recent trends favoring increasing application of small spacecraft for NASA missions include:

- Many small spacecraft technologies have miniaturized and grown in capability in recent years [2], in part driven by the rise of CubeSats;

- Rideshare opportunities for small spacecraft are rapidly increasing, offering more frequent low-cost launch opportunities to a wide range of orbits [3]; and

- U.S. and international aerospace stakeholders are increasing investment in small spacecraft, developing constellations as a lower-cost and lower-risk approach to providing global satellite services [4].

While the appeal of small spacecraft to fulfill needs within the commercial sector grows, challenges persist in the area of highly capable in-space propulsion. In recent years, NASA has applied significant resources towards funding small- and micro-spacecraft propulsion system developments in an attempt to address this need. However, while a handful of the commercial-sector developments are approaching flight readiness, most of these propulsion developments are unsurprisingly more appropriate for commercial low Earth orbit (LEO) applications than long-life deep space missions. This is a natural outcome of commercial industry offering a greater return on investment for businesses pursuing propulsion system developments. This is a positive outcome for U.S. commercial spaceflight in LEO, however unfortunate for NASA exploration and science missions requiring high reliability and very large delta$\mathrm{v}$ propulsive capability. So, even with considerable recent NASA investments in small-satellite propulsion, challenges continue to persist for NASA to identify viable propulsion technologies that will enable near-term small-spacecraft for NASA missions beyond LEO.

For NASA to pursue deep space exploration and science missions employing small-spacecraft, and benefit from the cost savings associated with rideshare opportunities, small spacecraft on-board propulsion systems must not only have sufficient capability to accommodate non-ideal initial launch trajectories, but also the propulsive capability to escape earth orbit and perform necessary maneuvers en route to their destinations. The state-of-the-art in high specific impulse, high reliability, in-space propulsion is xenon-fed Hall-effect and gridded-ion thrusters. Such systems have not only been demonstrated by NASA on the Dawn and Deep Space 1 missions, but they have also been employed throughout commercial spaceflight for decades. Xenon is a non-hazardous inert gas, storable at approximately 1.6 g/cc under pressure, and ionizes easily. The major drawbacks of xenon are its high cost and high storage pressure. Furthermore, since xenon is stored in a high-pressure vessel to achieve the desired storage density, few storage geometries are feasible, limiting packaging options within the tight confines of the small spacecraft. So, while xenon is well proven, and provides considerable performance capability, it still places unfortunate limitations on smallspacecraft developers.

In recent years, institutions around the globe, including NASA and the U.S. Air Force have given increased attention to iodine as a higher-density, lower-pressure alternative to xenon for highly volume-constrained missions requiring large delta-v propulsive capability. A useful metric by which to understand the benefit of iodine relative to xenon for volume-limited spacecraft is commonly known as density-Isp, where a thruster's specific impulse, Isp, is weighted by the specific gravity of the stored propellant. For a propulsion system with a fixed total impulse requirement, an improvement in density-Isp results in a reduction in propulsion system volume requirement. Alternatively, for a fixed propellant storage volume, raising the density-Isp of the propulsion hardware increases the delta-v capability of the spacecraft as long as spacecraft mass limitations are not exceeded. Investigations of Halleffect and gridded-ion thrusters with iodine propellant have consistently demonstrated thruster performance (i.e., specific impulse, thrust, and efficiency) highly similar to performance with xenon [6-8]. Thus, given a similar Isp between iodine and xenon propellants, but an ability to store iodine at triple the density of xenon, iodine can achieve a density-Isp triple that of a propulsion system operated on xenon. In short, if successfully implemented, iodine propellant would offer a significant boost in spacecraft propulsive capability compared the state-of-the-art xenon propellant with potentially no impact on the overall spacecraft size.

It is also worth noting that while secondary spacecraft are both volume and mass limited, rideshare mass availability continues to climb. For example, the ESPA ring, originally qualified for a $180 \mathrm{~kg}$ capacity per spacecraft, is in the process of being requalified for $300+\mathrm{kg}$ per spacecraft. Similarly, the ESPA-Grande will be able to accommodate well over $450 \mathrm{~kg}$ per spacecraft, rather than its original $300 \mathrm{~kg}$ [9]. Thus, while volume allowances for secondary spacecraft will likely remain unchanged in the near future, launch providers are offering greater 
accommodation to denser secondary payload spacecraft, which in turn favors use of denser spacecraft propellants such as iodine.

On the other hand, while iodine propellant has many advantages for mass and volume constrained spacecraft, there are numerous unique challenges that must first be overcome. Condensable propellants like iodine raise concern of propellant deposition on spacecraft surfaces such as solar panels and optics. Iodine is also reactive with most materials, creating new and potentially costly development challenges to select appropriate materials for both the propulsion system and other spacecraft subsystems exposed to the propellant/plume during flight. The iodine feed system also has unique challenges associated with the low-pressure propellant, such as assuring adequate propellant delivery and fine flow control capability. An iodine feed system and thruster may also require greater electrical power to keep wetted surfaces sufficiently heated to avoid iodine deposition and clogging throughout the propulsion system. Furthermore, there are high-temperature iodine material compatibility considerations that apply to both the thruster $\left(>500^{\circ} \mathrm{C}\right)$ and cathode $\left(>1000^{\circ} \mathrm{C}\right)$. Finally, there are numerous concerns regarding handling of iodine during ground testing (e.g. storage, transfer, health risks, test facility material compatibility, procedures, etc.) and how best to acceptance test iodine fed propulsion systems prior to flight.

This paper will review recent iodine-fed electric propulsion investigations at NASA Glenn Research Center, which culminated in a 1,174-hour hybrid iodine-xenon propulsion system durability demonstration (iodine fed thruster with xenon fed cathode). Investigations sought to determine iodine compatibility of state-of-the-art (SOA) BaO hollow cathodes, iodine compatibility of some relevant ground facility and spaceflight materials, as well as develop new iodine compatible feed system and test facility hardware in preparation for the durability demonstration.

\section{BaO Cathode Investigations}

A Hall-effect thruster requires propellant fed to both the thruster and cathode for operation. While the working fluid fed to the cathode does not necessarily need to be the same gaseous propellant fed to the thruster, carrying only a single propellant is preferable as the simplest solution. Thus, just as a xenon Hall-effect thruster operates with a xenon fed cathode, the ideal configuration for an iodine electric propulsion system would include an iodine-compatible cathode. However, identifying an iodine compatible cathode design appropriate for a Hall-effect propulsion system has proven very challenging. NASA GRC performed numerous tests of cathode assemblies (based on a GRC heritage design) that used SOA porous tungsten $\mathrm{BaO}-\mathrm{CaO}-\mathrm{Al}_{2} \mathrm{O}_{3}$ impregnated inserts with iodine propellant. One motivation was identification of a sufficiently iodine-compatible cathode configuration in advance of the minimum 1,000-hour durability demonstration. Another equally important motivation was to determine if a porous tungsten $\mathrm{BaO}-$ impregnated emitter could meet the requirements of NASA's Iodine Satellite (iSat) project [10], which was recently discontinued. Unfortunately, although numerous structural materials in the cathode assembly demonstrated an acceptable degree of compatibility over the evaluation period, the $\mathrm{BaO}$-impregnated emitters repeatedly failed to meet the longevity and performance requirements for either the durability demonstration or iSat. All cathode standalone tests were performed at NASA GRC's Vacuum Facility 2 (VF2). For the cathode test campaign, VF2 was equipped with both a xenon and iodine feed system, allowing rapid transition between the two propellants.

The first test performed (Test \#1) incorporated a cathode assembly without the $\mathrm{BaO}$ emitter installed. The aim was to first investigate the iodine compatibility of cathode assembly structural materials at operational temperatures. During Test \#1 the cathode assembly orifice plate was instrumented with a thermocouple. The cathode heater current was set to maintain an orifice plate temperature of $\sim 1000{ }^{\circ} \mathrm{C}$. During Test $\# 1$ iodine flow was passed through the cathode tube and orifice. Inspection of the cathode assembly hardware after approximately 24 hours of exposure to iodine at elevated temperature indicated that no component degradation was observable. There was no evidence of iodide formation/deposition or any remnant iodine deposits on the cathode components.

In Test \#2, a SOA porous tungsten $\mathrm{BaO}-\mathrm{CaO}-\mathrm{Al}_{2} \mathrm{O}_{3}$ impregnate emitter was installed inside the same cathode assembly. As with Test \#1, the heater current was set such that an orifice plate temperature of $\sim 1000{ }^{\circ} \mathrm{C}$ was maintained. Similar to Test \#1, iodine propellant was injected into the cathode tube. The aim of the test was to establish the emitter's iodine compatibility in the absence of an active plasma. The test duration was approximately 50 hours. Inspection of the cathode assembly after the conclusion of Test \#2 indicated:

- Almost complete depletion of the $\mathrm{BaO}$ impregnate at the emitter downstream surface (orifice plate end). This outcome will result in more difficulty achieving plasma ignition and will eventually lead to cathode end-of-life. Although impregnate depletion occurred, it is worth noting that sufficient impregnate remained, in theory, to allow for electron emission and meet iSat's minimal lifetime requirements. The rate of $\mathrm{BaO}$ depletion, however, was deemed far too great to support a 1000+ hour durability demonstration;

- Formation of an interesting dendritic structure on the upstream end of the insert was observed; and

- Significant deposition of impregnate material on the downstream surface of the cathode orifice plate: 
o Resulting in $\sim 50 \%$ reduction of effective orifice diameter (due to deposition in the orifice region); and

o Impregnate deposition reducing the effective gap between the cathode and keeper plate, which may result in premature voltage breakdown when cathode ignition is attempted.

The third test performed (Test \#3a) aimed to demonstrate cathode ignition and current extraction with iodine propellant. Prior to the introduction of iodine, a new cathode assembly was conditioned following NASA GRC standard cathode operating procedures. Initial cathode ignition was performed with xenon and the cathode was operated for $\sim 5$ hours to condition the insert surface. Characterization of the cathode assembly with xenon indicated nominal operation with ignition voltage magnitudes of $25 \mathrm{~V}$ to $50 \mathrm{~V}$. After establishing a baseline cathode operation with xenon, cathode operation with iodine was attempted, but erratic cathode behavior was immediately observed, where the ignition voltage was above $500 \mathrm{~V}$ and no stable steady-state operation with iodine was achieved. Additionally, after the insert was exposed to iodine, cathode operation when returned to xenon required ignition voltages that were approximately $500 \mathrm{~V}$, indicating cathode degradation had occurred.

After Test \#3a, several changes were incorporated in the same cathode assembly over a series of tests (designated Test \#3b-c), which included changes to the anode plate configuration, changes to the cathode-keeper gap, and the addition of "vent holes" on the keeper tube. These changes enabled the attainment of short-term steady-state operation with iodine propellant, but were characterized by inconsistent ignition voltages (frequently $>1 \mathrm{kV}$ ) and unreliable operation. Test \#3b-c indicated that operation of a $\mathrm{BaO}-\mathrm{CaO}-\mathrm{Al}_{2} \mathrm{O}_{3}$ impregnate cathode with iodine working gas leads to accelerated degradation of the cathode. The degradation is indicated by severe etching and porosity of the insert. To address the possibility that tests \#3b-c suffered from unintended oxygen contamination, a final new cathode was assembled based on the most promising configuration from the earlier test sequences. After conditioning and demonstrating nominal performance on xenon, Test \#3d achieved 14 keeper ignition cycles on iodine between $250 \mathrm{~V}$ and 500V. However, stable current extraction to an anode plate could not be achieved.

Figure 1a shows a macro-view of a typical insert after operating for $<1$ hours with iodine. The region shown indicates the severe porosity and rough nature of the insert. In addition to the porosity, a notable depletion of $\mathrm{BaO}$ is observed throughout the bulk of the insert. Figure $1 \mathrm{~b}$ shows a detailed-view of the depleted impregnate. Remaining impregnate within the iodine operated cathode consists primarily of $\mathrm{Al}_{2} \mathrm{O}_{3}$ and $\mathrm{CaO}$ with depleted levels of $\mathrm{BaO}$, as measured with energy dispersive spectroscopy. The blue ellipse in Figure 1a highlights a region of Ba tungstate formation along the inner emission surface, possibly indicating the mechanism by which barium is being depleted.

a)

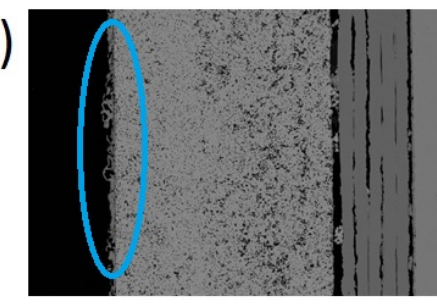

c)

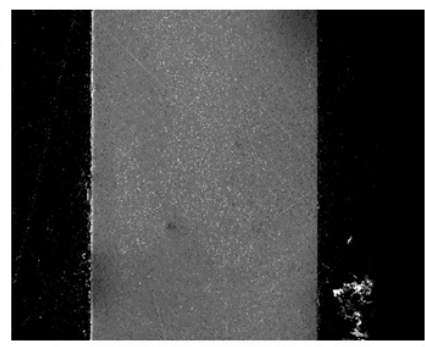

b)

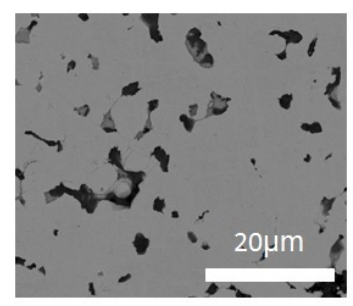

d)

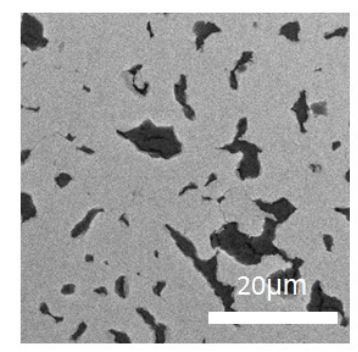

Figure 1: SEM of typical polished cross-sectioned cathode insert. a) Macro-view of cathode insert after iodine operation, and b) detailed-view of cathode insert after iodine operation. c) Macro-view of the pristine insert from a xenon cathode operated in proximity to an iodine thruster, and d) detailed-view of the pristine insert from a xenon cathode operated in proximity to an iodine thruster.

Cathode inspection after test \#3a-d indicated notable quantities of foreign deposits on both cathode and keeper orifices after operating cathodes on iodine. Figure 2a shows a keeper orifice partially obscured with a barium and iodine-containing compound. Likewise deposits of barium containing compounds can be observed in Figure 2c on a cathode orifice plate, Figure $2 \mathrm{~b}$ is included as a reference image of the orifice plate pre-operation with iodine. 
a)

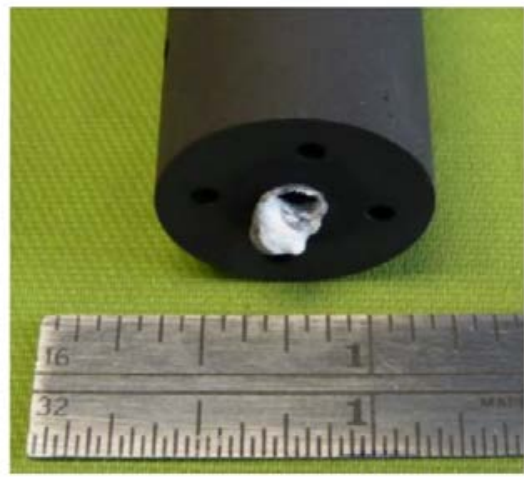

b)

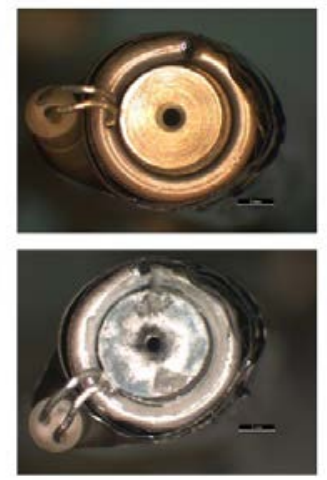

Figure 2: a) Keeper orifice after operating on iodine deposited with barium and iodine containing compound, b) cathode orifice plate before operating on iodine, and c) cathode orifice plate after operating on iodine and coated in barium compounds.

The team's consensus based on the high rate of barium depletion observed during testing, as well as unreliable cathode ignition and steady-state operation with iodine, is that a cathode based on $\mathrm{BaO}-\mathrm{CaO}-\mathrm{Al}_{2} \mathrm{O}_{3}$ impregnate was inadequate to meet either the long duration iodine propulsion system demonstration, or iSat mission requirements. While the cathode needs for the iSat mission could not be met, an alternative strategy was devised for the minimum 1000-hour durability demonstration, which involved employing a xenon-fed cathode with an iodine-fed Hall-effect thruster. For flight applications employing iodine, while a hybrid feed system is not the simplest solution, it will still achieve a significant reduction in the total propellant tank volume compared to an all-xenon system, since the cathode flow rate is typically on the order of $7 \%$ of the total mass flow. Given the many near-term challenges associated with identifying a sufficiently iodine-compatible cathode, an iodine-fed thruster with xenon-fed cathode offers a likely near-term solution that still captures the benefits of iodine's higher density and suitability for conformal tank designs.

For the long duration demonstration, a new cathode assembly was fabricated with a configuration that provides stable cathode operation for extraction currents between 0.5 and 3A. After completion of the 1,174-hour demonstration, the insert was removed from the cathode assembly and it was sectioned and analyzed in detail to determine whether any degradation of the insert occurred due to its proximity to the iodine-fed thruster. The cathode insert was not found to be depleted in barium, etched, nor porous, and no iodine was detected within the cathode assembly. Figures 1c and 1d (previous page) show the positive outcome of a cathode operated for 1,174-hours mostly at a discharge current of $2 \mathrm{~A}$ with a $0.5 \mathrm{~A}$ keeper current in close proximity to an iodine thruster. No degradation resulting from the close proximity between the xenon-fed cathode and iodine-fed main discharge was detected. Although an all-iodine system is ultimately desired to minimize propulsion system complexity, a hybrid iodine-xenon system demonstrates long-term cathode reliability and a compelling near-term solution to increase small-spacecraft propulsion system density-Isp as research into iodine compatible cathodes is further pursued.

\section{Iodine Material Compatibility Studies}

A primary challenge for implementation of iodine as an in-space propellant is resolution of material compatibility concerns with the propulsion system, ground test facilities, and the spacecraft. While properties and reactivity of iodine are overall well-described in literature, little is specifically known regarding iodine's behavior in space environments with the wide range of plausible spacecraft and propulsion system materials. It is also not well understood how best to modify existing ground test facilities or construct new test facilities to provide adequate resistance to iodine's corrosive potential. Without such understanding, acceptance of iodine as a viable alternative to xenon, regardless of its demonstrated performance benefits, will be a major obstacle to implementation of this potentially enabling technology. This work adds to the existing body of iodine literature, but focusing on iodine reactivity in a context applicable to spacecraft and vacuum test facilities.

The chemical, structural and microstructural behavior of steels (304, 316 and A36), titanium-aluminum alloy (Ti$\mathrm{Al}, 6 \mathrm{AL}-4 \mathrm{~V}$ ), and aluminum-magnesium alloy (Al-Mg, 6061) were probed after exposure to iodine laminar flow. The titanium, aluminum, and stainless steel alloys were selected due to their frequent use in spacecraft and ground test facilities. Furthermore, the interior lining of the GRC vacuum test facilities employed in this work were determined to be 304 stainless steel and thus of immediate relevance. The A36 low-carbon steel was selected as an exemplary steel alloy to represent common components found in bearings, translation stages, vacuum pumps, and other vacuum test facility equipment. Two coatings were investigated for their corrosion inhibition properties, SilcoTek ${ }^{\circledR}$ 
Corporation's Silcolloy ${ }^{\circledR}$ and Dursan ${ }^{\circledR}$. Test samples were created for each material and material-coating combination. Material sample exposures were carried out in a custom-built Iodine Vapor RIG (IVR) at $300{ }^{\circ} \mathrm{C}$ with an iodine laminar vapor flow of $1 \mathrm{mg} \cdot \mathrm{min}^{-1}$, carried by $145 \mathrm{~mL} \cdot \mathrm{min}^{-1}$ argon gas, for 5,15 and 30 days. The elevated temperature increases the rate of reactivity for investigative purposes, but also the temperature is more representative of electric propulsion systems at operational temperature. Samples were characterized before and after the experiments using gravimetric analysis, X-ray diffraction (XRD) and cross-section electron microscopy analysis coupled with energy dispersive X-ray spectroscopy (EDS). The aspect of the work described here primarily focuses on the gravimetric analyses. Greater detail on the work summarized in this section has been published as a NASA technical memorandum [11]. The iodine material compatibility work is on-going at NASA GRC, so additional reporting of results is expected.

\section{A. Materials}

The materials used in this work are divided into two groups. Group I - Metallic Materials consisting of stainless steels 304, 316 and A36 (low carbon steel), and 6061 aluminum alloy and 6AL-4V titanium aluminum (TiAl) alloy. The metallic sheets were fabricated by water jet into square shapes 0.5 ” x 0.5 " with 0.075 ” mounting holes (Figure 3). Group II - Coatings consisting of Silcolloy ${ }^{\circledR}$ (silicon based coating material, oxidation resistant up to $1000{ }^{\circ} \mathrm{C}$ ) and Dursan ${ }^{\circledR}$ (silicon based coating material functionalized with oxygen and carbon, corrosion and abrasion resistant up to $450{ }^{\circ} \mathrm{C}$ ), both coatings were applied on the samples by Silcotek Co., Bellefonte, PA. The coating Silcolloy ${ }^{\circledR}$ was applied on the steels 304, 316 and A36, and on TiAl alloy. Dursan ${ }^{\circledR}$ coating was also applied on stainless steel 304. The aluminum alloy was not coated due to the high temperature requirement of the chemical vapor deposition process and aluminum's low temperature properties.

All samples were cleaned with a detergent solution, rinsed with deionized water, and ultrasonic cleaned in acetone and ethanol prior the experiments. Samples were weighed on an analytical balance (Sartorius model 1712 MP8, Göttingen, Germany) ( \pm 0.0003) before and after the exposure to the iodine vapor laminar flow.

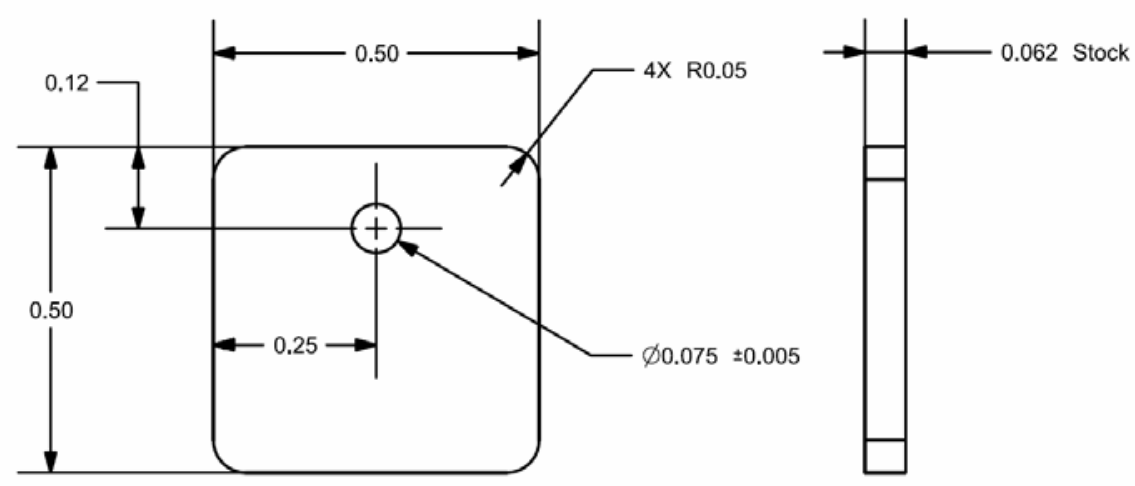

Figure 3: Material test sample dimensions (water jet from plate stock). Dimensions in inches.

\section{B. Iodine Vapor Laminar Flow Exposure Apparatus and Procedure}

Samples were placed on a sample holder illustrated in Figure 4. The sample holder consisted of a semicircular alumina tube with perpendicular gold wires suspended on the tube. Samples were directly suspended from the Au rod using alumina spacers to separate them. The sample holder was placed inside of the quartz tube of a tubular furnace. The furnace was sealed and flushed with argon at $145 \mathrm{~mL} \cdot \mathrm{min}^{-1}$ while the temperature was raised to $300{ }^{\circ} \mathrm{C}$ and kept for about $1 \mathrm{~h}$ before the iodine laminar flow. The experiment started when an empty Erlenmeyer flask sitting on a hot plate at $\sim 50{ }^{\circ} \mathrm{C}$ was replaced by another Erlenmeyer flask containing solid iodine. The Erlenmeyer flask containing iodine was replaced by an empty one to stop the iodine flow at the end of the experiment. Each batch of samples were exposed to an iodine laminar vapor flow of $\sim 1 \mathrm{mg} \cdot \mathrm{min}^{-1}$, carried by $145 \mathrm{~mL} \cdot \mathrm{min}^{-1}$ argon gas, for 5,15 and 30 days. The test apparatus is illustrated in Figure 5. 


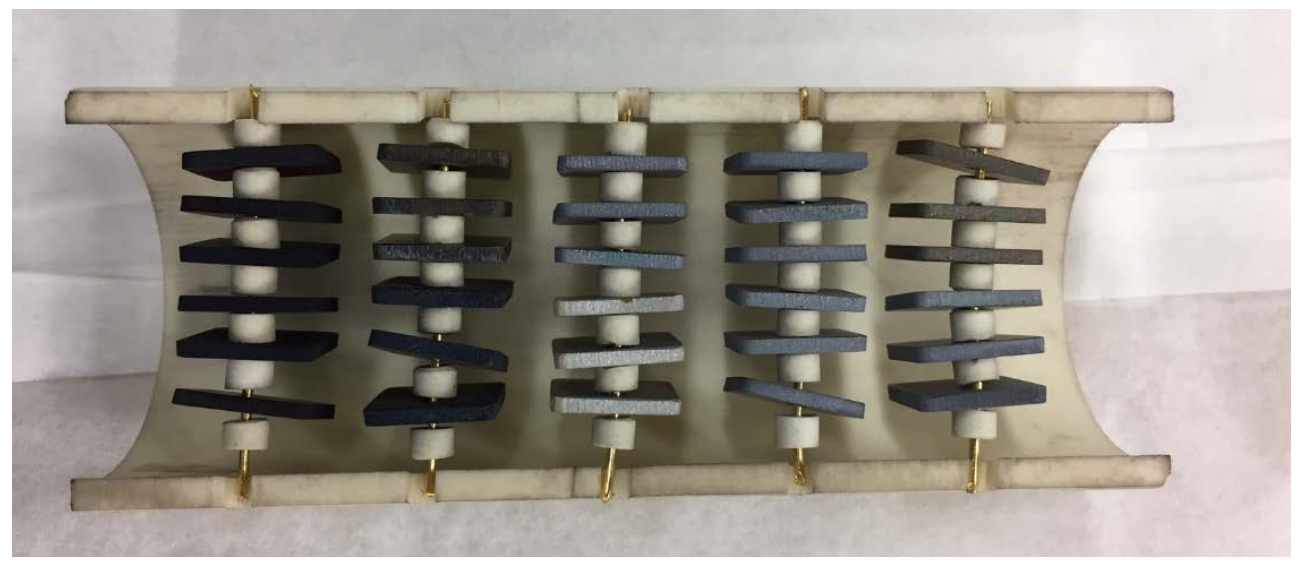

Figure 4: Alumina sample holder with coupon samples suspended with perpendicular gold wires. The samples were separated by alumina spacers.

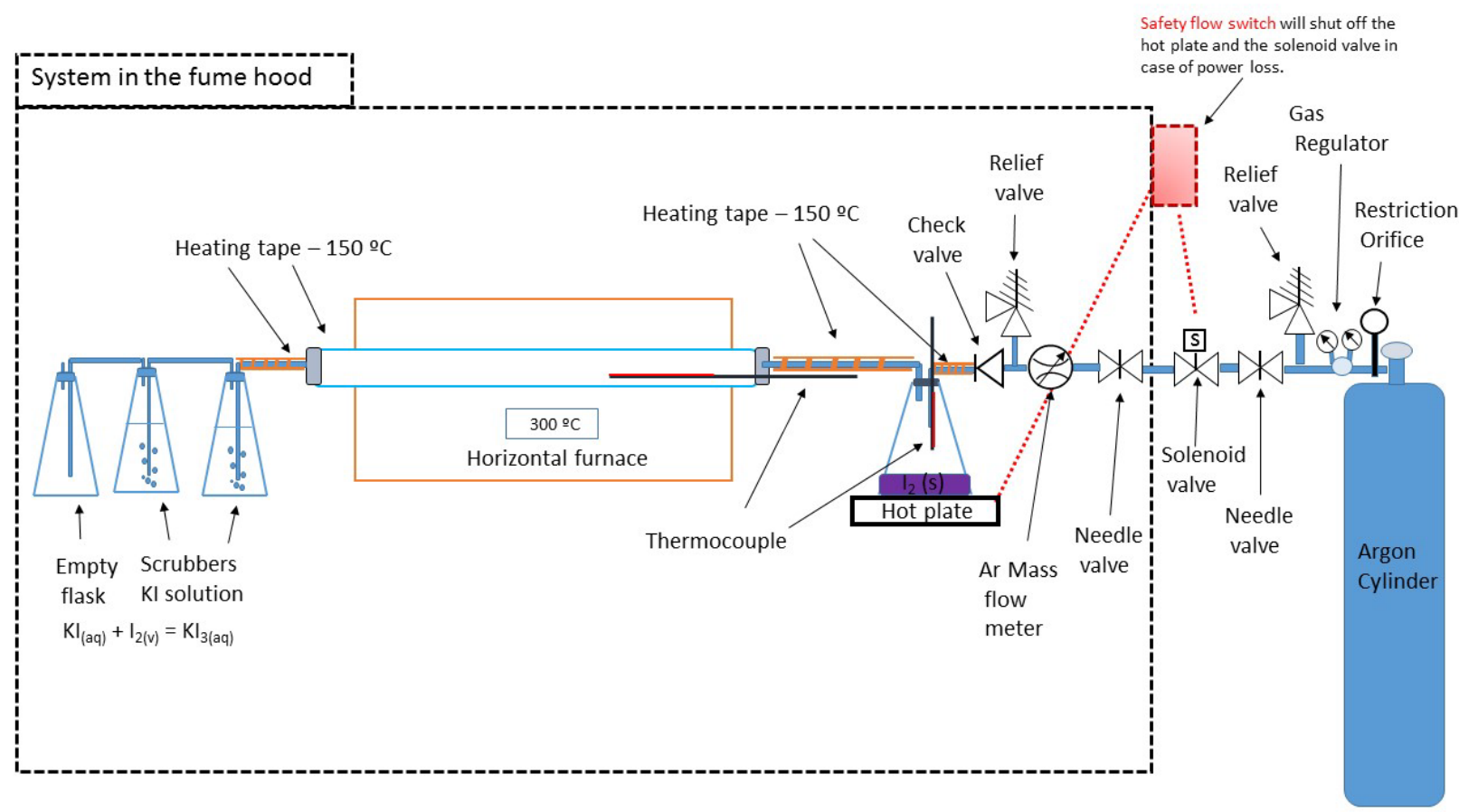

Figure 5: Iodine Vapor Rig. Argon carrier gas flows at $145 \mathrm{~mL} \cdot \mathrm{min}^{-1}$ through an Erlenmeyer flask containing solid/vapor iodine heated at $\sim 50{ }^{\circ} \mathrm{C}$. Iodine vapor is carried by argon through heated stainless steel lines kept at $\sim 150^{\circ} \mathrm{C}$ and the quartz tube inserted in a tubular furnace heated at $300^{\circ} \mathrm{C}$. Iodine vapor was retained as potassium triiodide in a $0.1 \mathrm{~mol} \cdot \mathrm{L}^{-1}$ potassium iodide solution.

\section{Sample Characterization}

After exposure the samples were analyzed by X-ray diffraction (XRD) on a Panalytical Empyrean diffractometer (PANalytical, Lelyweg 1, Netherlands) and by Field Emission Scanning Electron Microscope (FE-SEM) Hitachi S4700-II (Hitachi High Technologies, Gaithersburg, MD) equipped with energy dispersive X-ray spectroscopy (EDS) (EDAX, Mahwah, NJ), a secondary electron detector (SE), and a backscatter electron detector (BSE). For FE-SEM analysis, samples were mounted in a PolyFast ${ }^{\circledR}$ resin, polished using a non-aqueous solution. A Focused Ion Beam Scanning Electron Microscope (FIB-SEM) equipped with Gemini electron beam column (Carl Zeiss AG, Oberkochen, Germany) was also used to characterize some of the coated samples. The coupon samples were weighed before and after exposure to iodine and then normalized to unit area by dividing the weight change by the total area of a particular sample. This analysis is used to determine weight gain or loss per area of the samples due to reactions occurring 
between the iodine vapor and the solid phase. The assessment of the results of the gravimetric analysis can be used to determine the potential material candidates for use in an iodine atmospheric condition. All samples were tested in triplicate to estimate statistical uncertainty.

\section{Gravimetric Analyses}

A weight gain per area was observed for the steel samples exposed to iodine laminar flow (Figure 6). This weight gain is usually related to scale or oxide growth. Stainless steel 316 exhibited the lowest weight gain per area followed by stainless steel 304 and carbon steel A36 when individual data points are compared. The weight per area of carbon steel A36 increased $0.7 \pm 0.1 \mathrm{mg} \mathrm{cm}^{-2}$ from 5 to 15 days and decreased $0.7 \pm 0.1 \mathrm{mg} \mathrm{cm}^{-2}$ from 15 to 30 days. From 5 to 30 days, the weight gain per area of stainless steels 304 and 316 slightly increased by $0.2 \pm 0.1 \mathrm{mg} \mathrm{cm}^{-2}$ and $0.3 \pm$ $0.1 \mathrm{mg} \mathrm{cm}^{-2}$, respectively. Additional data points are required to calculate the weight gain rate of the steel samples.

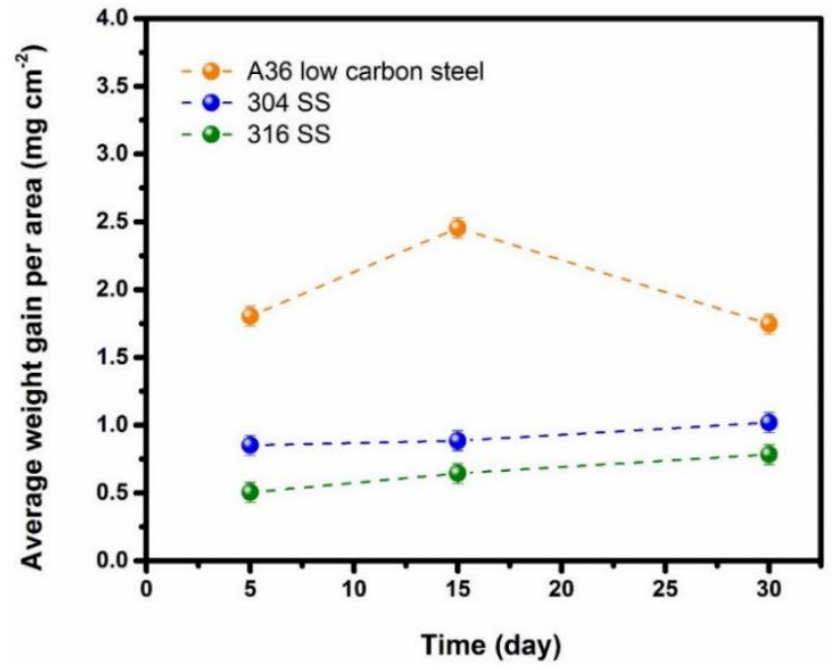

Figure 6: Weight change per area vs. time for steels exposed to iodine laminar flow at $300{ }^{\circ} \mathrm{C}$. Dashed lines are added to act as guide to the eyes only.

Figure 7 shows the weight loss per area of 6061 aluminum alloy and 6AL-4V titanium aluminum (TiAl) alloy samples. A slight decrease of $0.5 \pm 0.1 \mathrm{mg} \mathrm{cm}^{-2}$ in the weight of the TiAl sample is observed from 5 to 15 days. At the same exposure lengths, AlMg alloy sample had a much more pronounced weight loss of $2.0 \pm 0.1 \mathrm{mg} \mathrm{cm}^{-2}$. The weight loss (11.6 $\pm 0.1 \mathrm{mg} \mathrm{cm}^{-2}-\mathrm{TiAl}$ and $\left.8.4 \pm 0.1 \mathrm{mg} \mathrm{cm}^{-2}-\mathrm{AlMg}\right)$ for these samples are much steeper from 15 to 30 days.

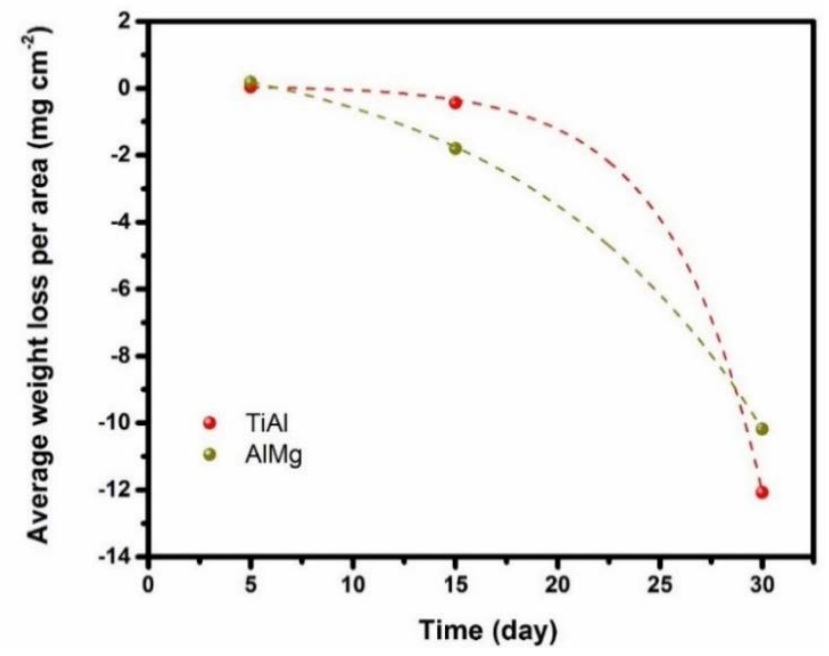

Figure 7: Weight change per area vs. time for alloys 6AL-4V (TiAl) and 6061 (aluminum containing 1 wt \% $\mathrm{Mg}$ ) exposed to iodine laminar flow at $300^{\circ} \mathrm{C}$. Dashed lines are added to act as guide to the eyes only. 
Allowing for experimental error, no weight change was observed for the samples 316 SS, A36 and AlTi coated with Silcolloy ${ }^{\circledR}$ and for the 304 SS sample coated with Dursan ${ }^{\circledR}$ exposed to the iodine laminar flow, Figure 8. Only the SS304 sample coated with Silcolloy ${ }^{\circledR}$ exhibited a weight gain of $1.02 \pm 0.07 \mathrm{mg} \mathrm{cm}^{-2}$.

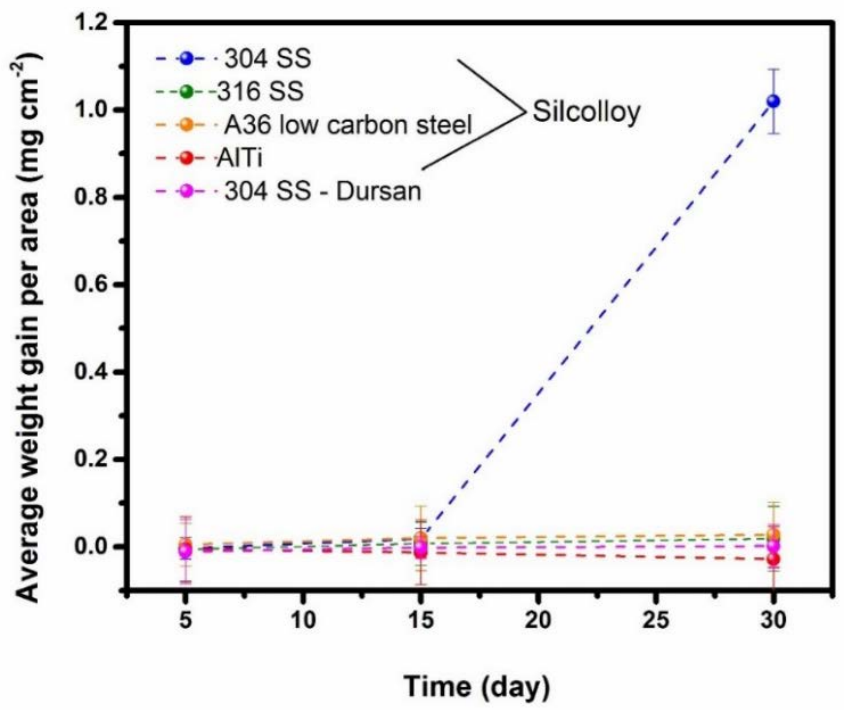

Figure 8: Weight change per area vs. time for alloys coated with Silcolloy ${ }^{\circledR}$ and Dursan ${ }^{\circledR}$ silicon based coatings exposed to iodine laminar flow at $300{ }^{\circ} \mathrm{C}$. Dashed lines are added to act as guide to the eyes only.

\section{E. Analysis of Austenitic and Carbon Steels}

The products formed on the steel coupon samples exposed to iodine vapor laminar flow are mainly oxides ( $\mathrm{FeNiCrO}_{4}$ and $\mathrm{Fe}_{2} \mathrm{O}_{3}$ from SS304 and SS316, and $\mathrm{Fe}_{3} \mathrm{O}_{4}$ from A36). The predicted thermodynamically stable compounds derived from FactSage are in good agreement with phases and elements detected by EDS and XRD diffraction techniques. Only small amounts of iodine were detected by EDS at the interface between the oxides and the base of the stainless steels 304 and 316. The formation of oxides on the base of the alloys clearly indicates that oxygen was present in the iodine vapor flow in the RIG system. Oxygen might have been introduced to the system during the beginning of the experiment when an empty Erlenmeyer flask was replaced by the one containing solid iodine. Oxygen may also be continually introduced by impurity from the argon cylinder or outgassing of apparatus materials. It is well known that even high purity argon still contains oxygen at ppm level which would be enough to cause oxidation to the extent observed in our studies. Considering that oxygen was present in our system, our experimental findings are in good agreement to those reported by Wren [12]. Wren proposed that corrosion of stainless steel exposed to iodine and air at room temperature is catalyzed by iodine. In their study, gaseous iodine was adsorbed and desorbed on stainless steel at room temperature and the surface of the samples were analyzed by energy dispersive $\mathrm{X}$-ray spectroscopy (EDS) and by X-ray photoelectron spectroscopy. They found a preferential diffusion of iron and the formation of Fe-I-O, and proposed the following reactions between stainless steel, air and iodine.

$$
\begin{array}{cc}
\mathrm{Fe}+\mathrm{I}_{2}=\mathrm{FeI}_{2} & \text { Eqn. } 1 \\
\mathrm{FeI}_{2}+\frac{y}{2} \mathrm{O}_{2}=\mathrm{FeI}_{x} \mathrm{O}_{y}+\left(1-\frac{x}{2}\right) \mathrm{I}_{2} & \text { Eqn. } 2
\end{array}
$$

in which $\mathrm{FeI}_{\mathrm{x}} \mathrm{O}_{\mathrm{y}}$ is composed of iron iodides and iron oxides. They also stated that the $\mathrm{FeI}_{\mathrm{x}} \mathrm{O}_{\mathrm{y}}$ phase mixture could react with more oxygen to release iodine. Their findings corroborates well with our results obtained by XRD and EDS analysis although our samples were exposed to a higher temperature $\left(300^{\circ} \mathrm{C}\right)$ and in a much lower oxygen partial pressure. The fact that XRD analysis detected only $\mathrm{FeNiCrO}_{4}$ and $\mathrm{Fe}_{2} \mathrm{O}_{3}$ phases in the stainless steel samples may be related to detection limit of this technique ( $1 \mathrm{wt} \%)$ considering that small amounts (2 - $4 \mathrm{wt} \%)$ of elemental iodine were detected by EDS in the scale of the stainless steel samples. It is also possible that iodine is adsorbed on the oxides of the scale. The formation of $\mathrm{FeNiCrO}_{4}$ indicates that iron, nickel and chromium initially reacts with iodine and are further oxidize to $\mathrm{FeNiCrO}_{4}$ and $\mathrm{Fe}_{2} \mathrm{O}_{3}$. Any iodide or iodate compounds formed would be carried by the iodine-argon flowing gases since these compounds in solid or liquid phases are volatile and also may have low decomposition temperatures (e.g. $\mathrm{Fe}\left(\mathrm{IO}_{3}\right)_{3}$ decomposes at $130{ }^{\circ} \mathrm{C}$ [13]. This reaction releases more iodine according to reaction (2) as it was proposed before by Wren [12] resulting in oxides with very low contents of iodine. For carbon steel A36, the 
main product of the reaction $\mathrm{Fe}_{3} \mathrm{O}_{4}$ and the absence of iodine indicates that $\mathrm{FeI}_{2}$ was completely converted to the oxide phase.

Although additional data points, especially at short exposition times, would be required to calculate the oxidation kinetics of the steel samples, it is possible to postulate that the last three data points of the weight gain per area in Figure 6 related to the oxidation of the steel samples would fit into a parabolic rate equation. The parabolic rate law describes a mass increase of a sample which is the case for oxidation of steels in this study. In this case, the rate of this reaction is mainly dominated by equation (2). From Figure 6, we conclude that the corrosion of the steels by iodine and oxygen increases in the order 316 SS $<$ A36 $<304$ SS. The highest corrosion resistance by SS 316 is related to its highest nickel content. Since iron preferentially diffuses to the surface for reaction, any effect leading to a decrease in the iron activity would increase the corrosion resistance of the alloy. As it is well known, the activity of iron diminishes as the nickel content in an alloy increases. Here, the stainless steel 316 has the highest content of nickel (316 SS -11 wt\% 304 SS 8 wt\% and A36 0 wt\%) and thus it would exhibit the lowest iron activity and higher corrosion resistance to iodine and oxygen atmosphere.

\section{F. Analysis of Aluminum and Titanium Based Alloys}

The absence of scale on the TiAl alloy sample exposed to iodine for 30 days indicates that metallic iodide $\left(\mathrm{M}_{\mathrm{x}} \mathrm{I}_{\mathrm{y}}\right.$, $\mathrm{M}=\mathrm{Al}^{3+}$ and $\mathrm{Ti}^{4+}$ ) compounds are the main products of the reaction between TiAl alloy sample and iodine vapor. Although these iodide compounds are solid phases, they exhibit elevated vapor pressures and might be carried by the laminar iodine flow. Relative small peak intensities of the secondary $\mathrm{TiO}_{2}$ phases in the $\mathrm{XRD}$ diffractograms indicates small amounts of $\mathrm{TiO}_{2}$ formed on the surface of the TiAl alloy. This indicates that oxygen partial pressure of oxygen in the rig system was not high enough to completely oxidize the $\mathrm{Ti}$ and $\mathrm{TiO}_{0.48}$ to $\mathrm{TiO}_{2}$ to form protective scales. Furthermore, a yellowish deposit found to be formed on the inner walls of the quartz furnace is another strong indication of the formation of volatile iodide compounds. EDS analysis confirmed that this deposit is mainly composed of titanium, aluminum, iodine and oxygen. In very low oxygen partial pressures, which is the case of this study, iodine vapor reacts with $\mathrm{TiAl}$ according to the reactions [14].

$$
\begin{gathered}
\mathrm{Ti}_{\mathrm{TiAl}}+\mathrm{I}_{2}(\mathrm{~g})=\mathrm{TiI}_{2}(\mathrm{~s}) \\
\mathrm{TiI}_{2}(\mathrm{~s})+\mathrm{O}_{2}=\mathrm{TiO}_{2}(s)+\mathrm{I}_{2}(\mathrm{~g})
\end{gathered}
$$

Eqn. 3

Eqn. 4

The weight loss per area of the TiAl would be governed by equation (3) and the best equation describing the net weight loss per area of the sample (Figure 7) would be a paralinear rate equation originally derived by Tredmon [15] and also used by Maloney\& McNallan [16] to describe two simultaneous reactions between chlorine, oxygen and cobalt at 927 ${ }^{\circ} \mathrm{C}(1200 \mathrm{~K})$ leading to increase (oxide scale growth, parabolic) and decrease (oxide consumption, linear) of sample mass. The differential equation describing this rate of change is

$$
\frac{d x}{d t}=\frac{K_{d}}{x}-K_{s}
$$

where $\mathrm{x}$ is the thickness of the scale, $\mathrm{K}_{\mathrm{d}}$ is the parabolic rate constant of the scale growth $\left(\mathrm{cm}^{2} / \mathrm{s}\right)$, and $\mathrm{K}_{\mathrm{s}}$ is the linear rate constant of the scale thickness decrease $(\mathrm{cm} / \mathrm{s})$.

The higher content of magnesium compared to the lower content of aluminum in the scale of the AlMg alloy sample indicates that magnesium is preferentially reacting with iodine and then is converted to oxide. It is also possible that aluminum is reacting with iodine to form aluminum iodine and then is further oxidized to oxide. From XRD diffraction it was not possible to confirm if the scale formed was composed of magnesium oxide since its diffraction peaks overlaps with the diffraction peaks of aluminum. Alumina was also not detected by XRD which might be related to lower detection limit of the diffractometer and the small amounts of the scale formed. Based on the experimental findings of this study and on the thermodynamic calculations reported by Donchev [14] the following reactions can be assumed for the reaction between the AlMg alloy sample, iodine and oxygen.

$$
\begin{gathered}
M g_{\mathrm{AlMg}}+\mathrm{I}_{2}(g)=\mathrm{MgI}_{2}(s) \\
\mathrm{MgI}_{2}(s)+1 / 2 \mathrm{O}_{2}=\mathrm{MgO}(\mathrm{s})+\mathrm{I}_{2}(g) \\
\mathrm{Al}_{\mathrm{AlMg}}+3 / 2 \mathrm{I}_{2}(g)=\mathrm{AlI}_{3}(l) \\
\mathrm{AlI}_{3}(\mathrm{l})+3 / 2 \mathrm{O}_{2}=\mathrm{Al}_{2} \mathrm{O}_{3}(s)+I_{2}(g)
\end{gathered}
$$

Eqn. 6

Eqn. 7

Eqn. 8

Eqn. 9

The weight loss per area of the AlMg alloy sample (Figure 7) suggests that the reaction is mostly governed by equations 6 and 8 followed by volatilization of their products $\mathrm{MgI}_{2}$ and $\mathrm{AlI}_{3}$. The paralinear law would also be the most adequate equation to fit the data points of Figure 7. 


\section{G. Analysis of Silcolloy and Dursan Coatings}

Silcolloy ${ }^{\circledR}$ deposited on stainless steel 316, carbon steel A36, and 6AL-4V TiAl alloy, and Dursan ${ }^{\circledR}$ applied on stainless steel 304, were effective in protecting the surface of the alloys against iodine-catalyzed oxygen corrosion. Stainless steel 304 coated with Silcolloy ${ }^{\circledR}$ was the only exception of protecting the base of alloy against corrosion by iodine. This conclusion is based on the sample exposed to iodine vapor for 30 days which exhibited a small increase $\left(1.02 \pm 0.07 \mathrm{mg} \mathrm{cm}^{-2}\right)$ in the mass of the sample and in the thickness $(142 \pm 33 \mathrm{~nm})$ of the Silcolloy ${ }^{\circledR}$ coating. We suspect that the coating failure to protect the base of the alloy may be related to surface preparation before coating deposition since this coating worked well in protecting the base of the other alloys. Further studies addressing surface preparation and coating deposition process are needed to address this anomaly.

The iron silicide crystalline phases detected by XRD analysis on the stainless steel 304 samples coated with Dursan $^{\circledR}$ and Silcolloy ${ }^{\circledR}$ are originated from reaction of silicon from the coating with iron from the base of the alloy during the deposition process. The results obtained by XRD analysis corroborate well with those obtained by EDS analysis. From EDS analysis, we also conclude that the constituent elements of alloys diffuse to the coating although not changing its corrosion protective characteristics.

\section{H. Summary}

All steels exposed for 30 days formed scales consisting mainly of metal (Cr, Fe, Ni) oxides showing different chemistry, microstructure and crystalline phases. Elemental iodine was only detected by EDS analysis in the scales of stainless steels 304 and 316. After 30 days, the Ti-Al exhibited no detectable scale, suggesting only a very thin film was formed. A scale consisting mainly of aluminum, iodine, and oxygen formed on the Al-Mg sample exposed to 30 days. Some pockets rich in magnesium, iodine and oxygen also formed in this Al-Mg alloy. Stainless steel 316, low carbon steel A36 and Ti-Al alloy coated with Silcolloy ${ }^{\circledR}$ and stainless steel 304 coated with Dursan ${ }^{\circledR}$ that were exposed for 30 days exhibited no oxidation. Stainless steel 304 coated with Silcolloy ${ }^{\circledR}$ exposed for 30 days did not exhibit corrosion although the sample gained weight and the coating exhibited expansion. The weight gain per area performance of the materials exposed in iodine laminar flow containing oxygen at impurity level for 5,15 and 30 days are reported from the lowest to the highest weight gain per area as follows: Steels: $316<304<\mathrm{A} 36$; Ti-Al-Mg based alloys: Al-Mg $<$ Ti-Al. Considering the experimental uncertainties, no weight change was observed for Stainless steel 316, low carbon steel A36 and Ti-Al alloy coated with Silcolloy ${ }^{\circledR}$ and stainless steel 304 coated with Dursan ${ }^{\circledR}$. The corrosion of the alloys is catalyzed by iodine in the presence of oxygen as impurity. The findings of these material studies, due to the presence of an oxygen impurity is most applicable to iodine material interactions as should be expected in vacuum test facilities and low Earth orbit. Similar testing with greater effort to eliminate oxygen impurity would be informative to understanding long-term iodine effects on spacecraft materials in deep-space. The corrosion of materials catalyzed by iodine in the presence of oxygen impurities, such as would be expected during any ground testing (qualification and acceptance) will be a major obstacle to interpret ground test results and perform typical preflight propulsion system testing and checkouts.

\section{Iodine Feed System}

Based on the material studies described in the prior section, GRC constructed multiple iodine vapor delivery feed systems fabricated from 316 stainless steel. While 316 SS is not itself highly resistant to corrosion by iodine, it provides a low cost alternative for development testing compared to the high nickel alloys that would most probably be used in construction of the wetted components of a flight iodine propulsion system. To forstall corrosion of the feed system components, the 316 SS was electropolished and chemical vapor deposition coated in amorphous silicon. While the silicon coating proved nearly impervious to iodine in the material studies, it should be understood that any mechanical damage to the coating will initiate corrosion of the substrate. For the GRC storage tanks and plumbing constructed, this was a common occurance at flanged surfaces with o-ring seals and compression fittings, where metal on metal contact occurs. Such mechanical damage can be mitigated at flanges in the future by use of gaskets, rather than o-rings. Mechanical damage to the coating also occurred in any attempt made to compact the iodine in the storage vessals to increase the crystaline iodine packing fraction, due to the abrasive properties of the crystals. Melting the iodine is a less aggressive and more effective means to maximizing the iodine packing fraction, and would pose little risk of damaging the coating. While 316 SS with a silicon coating was deemed more than adequate for the length of the durability demonstration described here, it would not be recommended to be solely relied upon for flight quality hardware. Given a suitable substrate, silicon coating could be used though as a secondary layer of protection to enhance material life, so long as failure of the coating did not pose significant risk to the propulsion system or mission. 
Silicon coating might also be appropriate for spacecraft surfaces requiring iodine protection and not subject to impingement by the plume (which would quickly deteriorate any such coating on the order of microns thick).

The first set of iodine tanks constructed were designed to hold approximately 500 grams of iodine. The location of the tank heater, the thickness of tank walls, the design of the iodine vapor port, and the tank mounting scheme were all accounted for to create appropriate thermal gradients to manage iodine sublimation and deposition within the tank. Rather than treating the tank as a uniform temperature structure, the tank is treated as a complex thermal environment with some surfaces determing the vapor pressure of iodine within the tank, while other surfaces (especially near the vapor port) deter iodine accumulation. The 500 gram iodine tanks were successfully utilized with all cathode tests described in Section II. The iodine material compatibility test rig has also been recently upgraded to use the tanks rather than the original erlenmeyer flasks.

After demonstrating the iodine storage tanks design principles at the 500 gram scale, the tank design was scaled for the 1,000-hour durability demonstration. The durability demonstration propellant tank was nominally designed to hold $10 \mathrm{~kg}$ of solid iodine propellant with additional volume for ullage. A load of $10 \mathrm{~kg}$ would provide upwards of 1200 hours of operation for the BHT-600-I at 300V and 2A. The propellant tank was designed to establish favorable temperature gradients within the iodine storage volume to yield a stable, but regulatable iodine vapor pressure at the storage tank vapor exit port. For the durability demonstration, the iodine flow rate to the Hall-effect thruster was simply regulated by altering the iodine vapor pressure within the storage vessal. As with the initial design, the larger tank's thermal gradients were established to prevent clogging at the vapor exit port. The tank was outfitted with redundant internal cartridge heaters and an external silicon tape heater. Temperatures were monitored at various locations using thermocouples. Iodine flow rate to the thruster was regulated by making adjustments to the power level of the various tank heaters, adjusting the temperature of key areas of the tank responsible for regulating the iodine vapor pressure.

A pair of customized solenoid valves were fabricated for the propulsion system assembly. One valve permitted xenon routing to the thruster to establish baseline operation against which iodine operation could be compared. The second valve isolated the iodine tank from the thruster when not in operation or operating with xenon. The valves were constructed by modifying stock valves manufactured by WIC Valve, San Jose, CA (Part\# 2PCV-1/4-24VDC). These valves are fabricated using Teflon ${ }^{\circledR}$ and EPDM wetted parts. Rather than risk melting the Teflon valve body by heating to prevent iodine deposition, the valve body was reproduced from silicon coated 316 SS, yet retaining the solenoid and stock internal Teflon ${ }^{\circledR}$ components. The EPDM o-rings were also replaced with viton. The modified valve bodies were also designed to house an integral cartidge heater and bolt on thermocouple. The valves proved both iodine resistant and resilient against iodine deposition and clogging throughout the durability demonstration. The valves were actuated using the stock normally-closed solenoid. Since the solenoids were operated continously in a vacuum environment without benefit of convective cooling, the solenoid's power disipation was derated. To meet the derating, the solenoids were operated by a hit-hold methodology which successfully prevented overheating, even as the valve bodies were heated to $130^{\circ} \mathrm{C}$ during continous operation. The valves were opened with a hit of $24 \mathrm{~V}$, and subsequently held by only $9 \mathrm{~V}$.

\section{GRC Vacuum Facility 7 Modifications}

The iodine electric propulsion system durability demonstration was conducted in Vacuum Facility 7 (VF7) at NASA GRC. VF7 is a 3-meter diameter by 5-meter long vacuum test facility with a $1 \times 10^{-7}$ torr base pressure (no load). The chamber has five 1-meter diameter oil diffusion pumps (ODP) providing a total theoretical pumping speed up to 125,000 liters per second at $10^{-6}$ torr. In practice, the pumping speed is significantly less due to the liquid nitrogen cold traps utilized to prevent oil back-streaming. In preparation for the iodine propulsion system durability demonstration, a number of facility modifications were completed.

Grafoil was applied to the chamber walls downstream of the thruster exit plane. The grafoil provides two primary benefits. First, the backsputter from the chamber walls is reduced during long-duration testing, which results in an accumulation of material on and around the thruster, increasing risk of electrical shorts or other thruster irregularities not consistent with in-space operation. Second, the grafoil slows deterioration of the stainless steel chamber walls resulting from interaction with energetic atomic and molecular iodine. The natural oxide layer formed on the 304 stainless walls in atmosphere provides some corrosion resistance against iodine. However, by allowing the energetic plume to impact directly on the chamber walls, rather than by shielding with a sacrificial material like grafoil, those natural oxides are continuously stripped from the surface, thereby exposing fresh metal and accelerating iodine's corrosive potential.

Similarly, stainless steel threaded studs on the chamber wall were covered with protective graphite nuts that were also used to secure the grafoil in place. Furthermore, immediately above the diffusion pumps, short grafoil tubes were 
constructed and installed to prevent plume impingement on the walls of the diffusion pump wells and liquid nitrogen cooled chevrons located between the chamber and diffusion pumps. The floor of the chamber was not covered in grafoil to permit ease of access to the chamber and experiment. However, the floor was covered with graphite felt prior to all testing. Ultimately, the graphite felt was deemed a poor choice for floor covering, as the graphite felt was slow to outgas iodine following testing, greatly slowing the decontamination process. While more cumbersome, use of grafoil or graphite plates on the chamber floor for future testing is recommended. The iodine propulsion system assembly as installed in the test facility is shown in Figure 9.

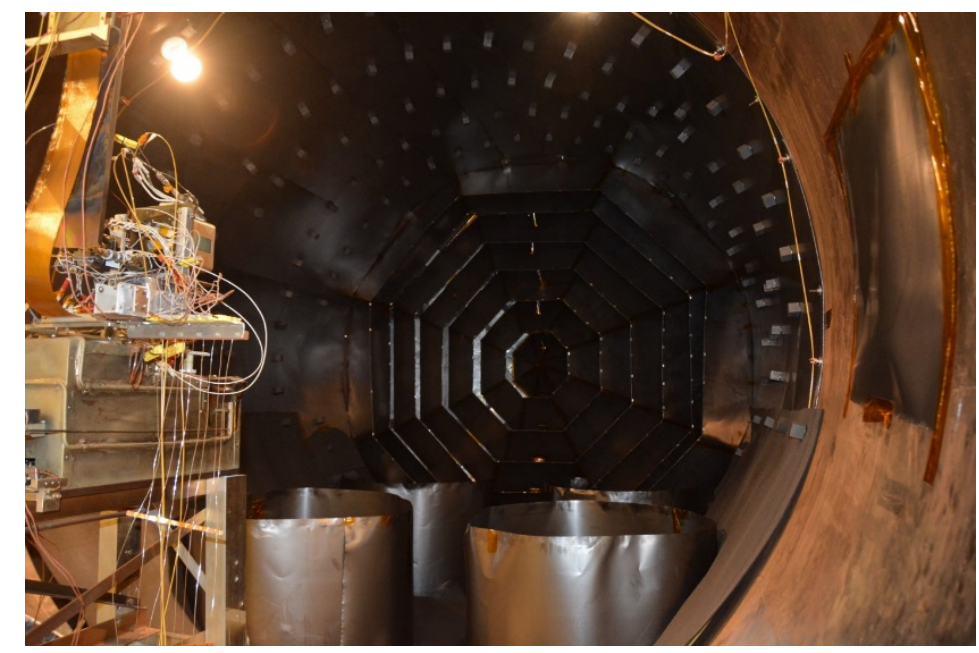

Figure 9: Iodine propulsion system assembly installed in GRC VF7 prior to 1,174-hour demonstration. All surfaces exposed to direct impingement of the iodine plume are protected with either grafoil, graphite felt, or solid graphite.

A chilled aluminum target, covered in a single layer of grafoil, was installed in the far end of the chamber as shown in Figure 9. A Polycold heat exchanger, with a cooling capacity capable of achieving -100C, was plumbed to the target to aid in accumulation of iodine during thruster operation. The diffusion pump chevrons were also cooled with liquid nitrogen, providing the primary iodine pumping surface and limiting iodine from entering the oil diffusion pumps. During operation, the liquid nitrogen cooled chevrons provided sufficient pumping capacity to maintain a chamber pressure of approximately $1 \times 10^{-5}$ torr.

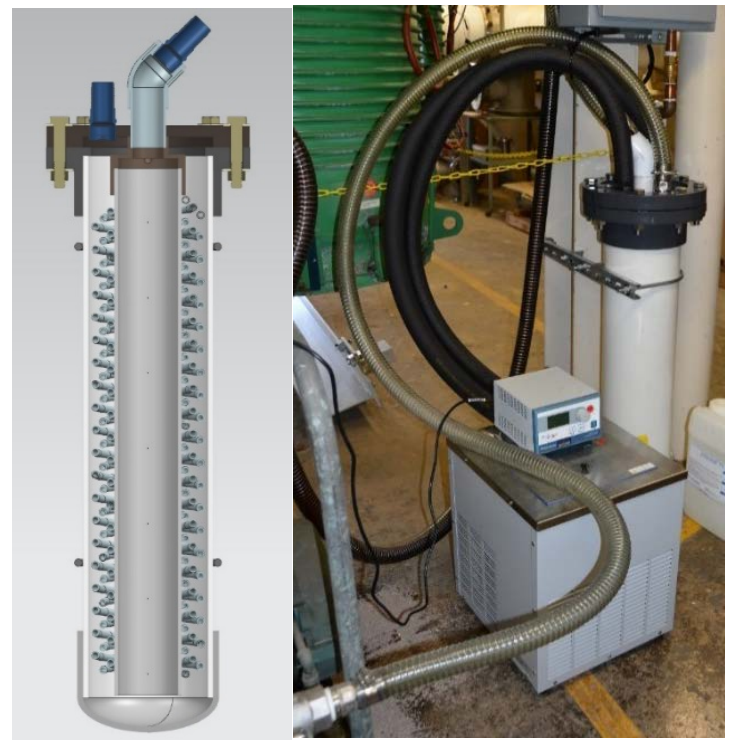

Figure 10: (Left) CAD model of the disposable iodine cold trap implemented for the demonstration. (Right) Photograph of the cold trap chilled with a PolyScience 9712, between VF7 and a Stokes 149 vacuum pump. 
Extraction of the iodine post-test was conducted by sealing the chamber through the use of gate valves, then pumping the iodine toward a Stokes 149 sacrificial vacuum pump (salvaged from being excessed). The liquid-nitrogen cooled chevrons were allowed to warm to room temperature, which results in an iodine vapor pressure of approximately 0.2 torr. A small gas flow of dry-nitrogen was introduced into the chamber to aid in circulation and evacuation of the iodine. To capture the iodine before reaching the Stokes 149, a disposable cold trap was assembled from PVC and polyethylene tubing as shown in Figure 10. A PolyScience 9712 chiller with a temperature capability of -40C circulated a solution of 50/50 water and glycol through the cold trap. A small percentage of the iodine was still capable of circumventing the cold trap, but was largely collected in the pumps oil, requiring regular pump oil changes following iodine extraction. The cold trap effectiveness would be increased in the future by employing a chiller with a lower temperature limit, however nothing better was immediately available at the time of the demonstration. Following completion of the iodine durability demonstration, the cold trap was sealed and properly disposed.

\section{Durability Demonstration Test Apparatus}

The thruster implemented in the iodine propulsion system durability demonstration was the Busek BHT-600-I. In the U.S., Busek is leading the development of iodine-compatible electric propulsion technologies [6-8]. Busek has demonstrated iodine electric propulsion at numerous power scales with both Hall-effect and gridded-ion thrusters. The BHT-600-I is similar to Busek's BHT-600, but with some alternative materials and coatings to improve iodine compatiblity. One aim of the durability demonstration was to acertain the effectiveness of the material and coating changes to the BHT-600 for long-term use with iodine propellant.

The cathode implemented in the long-duration demonstration was constructed by GRC around a porous tungsten $\mathrm{BaO}-\mathrm{CaO}-\mathrm{Al}_{2} \mathrm{O}_{3}$ impregnated emitter. As described earlier in Section II, because of a demonstrated lack of compatibility with iodine propellant, the decision was made to operate the propulsion system as a hybrid. While the thruster had a dedicated iodine storage tank and feed system installed in the vacuum test facility (on the thrust stand), xenon for the cathode was plumbed from an external xenon laboratory feed system. The propulsion system configuration for the long-duration test is illustrated schematically in Figure 11.

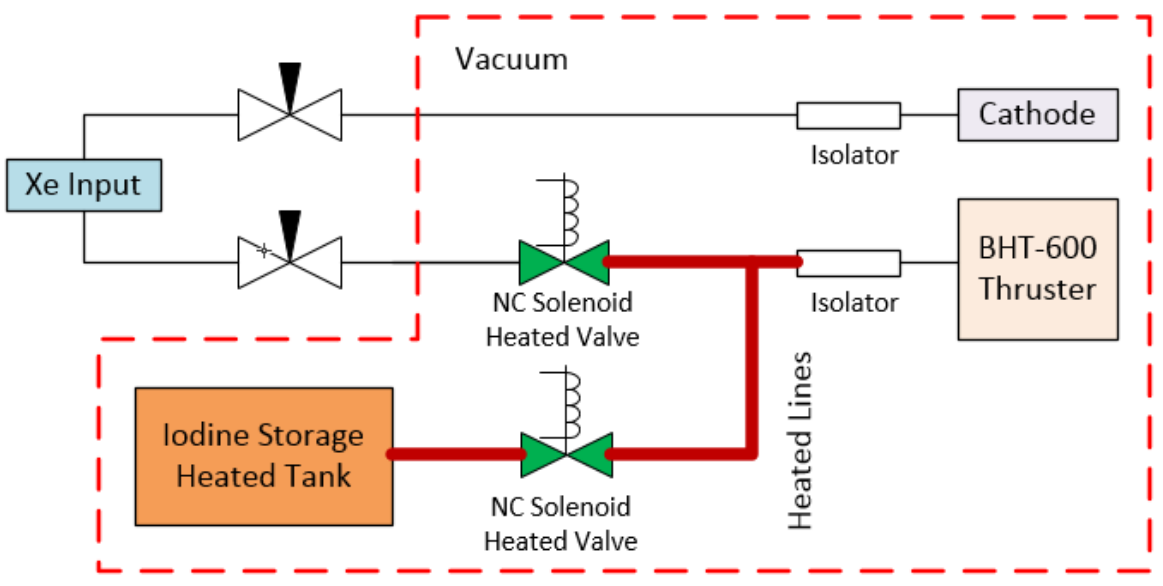

Figure 11: Schematic of iodine propulsion system demonstration test setup. Components illustrated inside the dashed line are located inside GRC's Vacuum Facility 7 (VF7) and mounted on the test facility thrust stand.

All tubing between the iodine storage tank and thruster was constructed from nickel alloy C276. Fittings employed throughout the feed system were 316 SS compression fittings as supplied by Swagelok Company. A silicon coating (SilcoTek Silcolloy ${ }^{\circledR} 1000$ ) was applied to all fittings for added iodine resistance prior to assembly. Only the compression fittings were coated, not the ferrules, as coating the ferrules would have risked leaks at the compression interfaces as the ferrules deformed. No pressure measurements were made within the iodine feed system. While pressure data was of interest, inclusion of a pressure sensor was deemed an unnecessary risk and not required for propulsion system operation. Additionally, iodine vapor pressure can be reasonably well predicted based on the iodine storage tank regulating temperature. The iodine flow rate was regulated to provide continuous thruster power by monitoring the discharge current (not a direct iodine flow measurement).

The thruster discharge, cathode, magnets, and keeper were all powered by laboratory TDK-Lamda power supplies. The initial demonstration called for use of a Busek 600W compact PPU currently under-development. However, the 
PPU development was not complete at the time of the durability demonstration. Based on the operational characteristics of the hybrid iodine-xenon system tested here, it is anticipated that if the PPU works as intended with all-xenon, it should work well with a hybrid Hall-effect propulsion system configuration.

Data was collected using a Keysight 34972 Data Logger, two 20-channel multiplexer modules, and Keysight's BenchLink ${ }^{\circledR}$ data collection software.
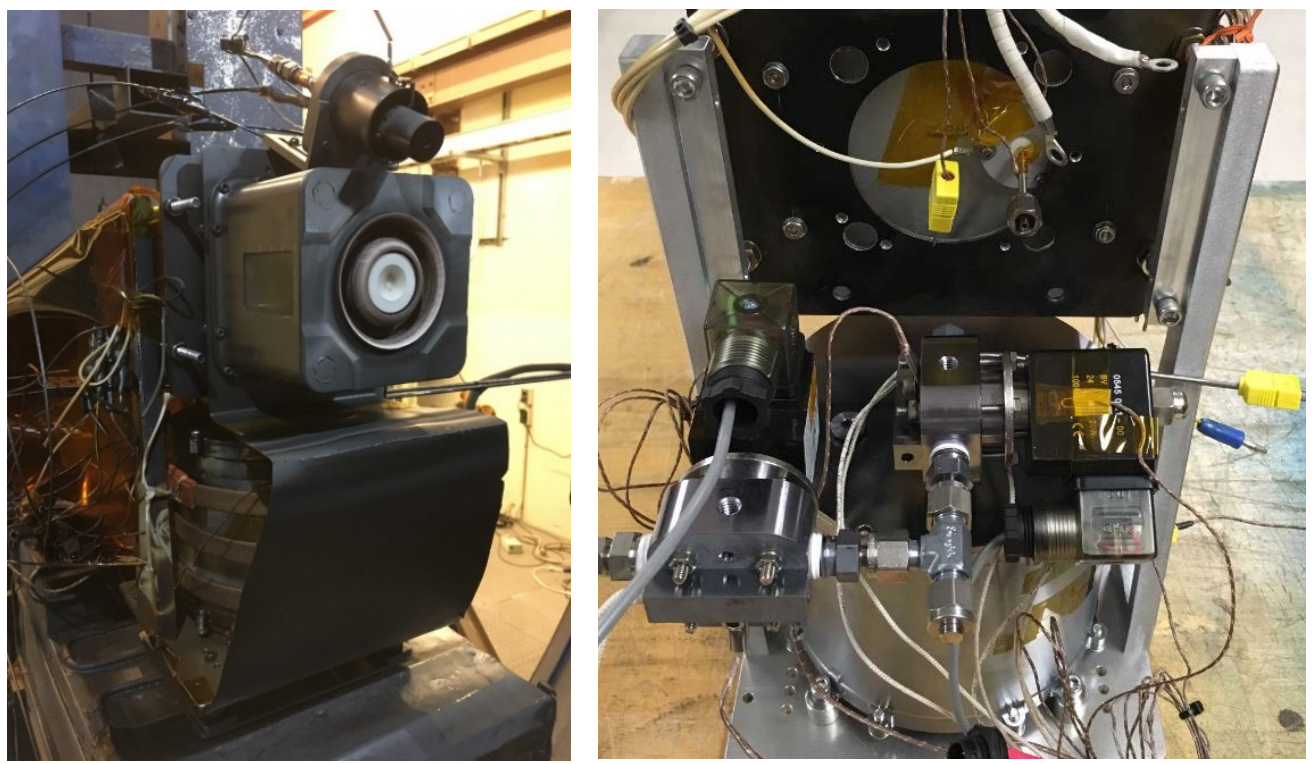

Figure 12: (Left) Iodine propulsion system assembly mounted in GRC Vacuum Facility 7 (VF7). (Right) Partially assembled iodine feed system including tank, valves, and fittings.

A photograph of the iodine propulsion system assembly is shown in Figure 12. The GRC xenon fed cathode was mounted at 12 o'clock with respect to the BHT-600-I thruster. The thruster was mounted above and slightly forward of the iodine storage tank to nominally put the propulsion system assembly center of mass directly above the thrust stand. To avoid potential complications related to graphite backsputter from the test facility walls, the propulsion system assembly was strategically protected with grafoil and kapton shields.

\section{Iodine Propulsion System Demonstration Results and Discussion}

In preparation for the long-duration demonstration, the iodine storage tank was loaded with 5,037 grams of iodine on 29 June 2017. Although the iodine tank was designed with the intention of loading $10 \mathrm{~kg}$, equipment necessary to solidify the iodine crystals was not yet available prior to the onset of the demonstration. As a result, loading 99.99+\% crystalline iodine as supplied by Thermo Fisher Scientific Chemicals yielded approximately a 50\% packing fraction. A photograph of the iodine tank (a) new and unloaded, (b) loaded with $5 \mathrm{~kg}$ crystalline iodine, and (c) after the first 567 hours of testing are shown in Figure 13. At 567 hours, the vacuum facility was decontaminated, the storage tank was refilled with an additional 4,996 grams, and the demonstration was resumed. Note in Figure 7c that no degradation of the silicon-coated storage tank walls was observed, except minor corrosion at the flange-lid interface. Additionally, thruster operation continued reliably until only the last few grams of iodine shown in Figure 7c remained.

The iodine demonstration was initiated on 25 July 2017. Prior to flowing iodine, a baseline performance map of the BHT-600-I was established with xenon propellant. At 300V and 2A, with an anode xenon flow rate of $2.52 \mathrm{mg} / \mathrm{s}$ and cathode xenon flow rate of $0.2 \mathrm{mg} / \mathrm{s}$, a thrust was measured of $41.3 \mathrm{mN}$, yielding a specific impulse of 1550 seconds. Similar xenon measurements were made periodically throughout the duration of the iodine demonstration to assess performance against a xenon baseline. Periodic xenon measurements were deemed necessary as no capability was integrated into the test setup to measure instantaneous iodine flow rate, limiting iodine performance assessment to thrust and an average specific impulse. The periodic xenon performance maps are tabulated in Table 1 for various discharge voltages. 


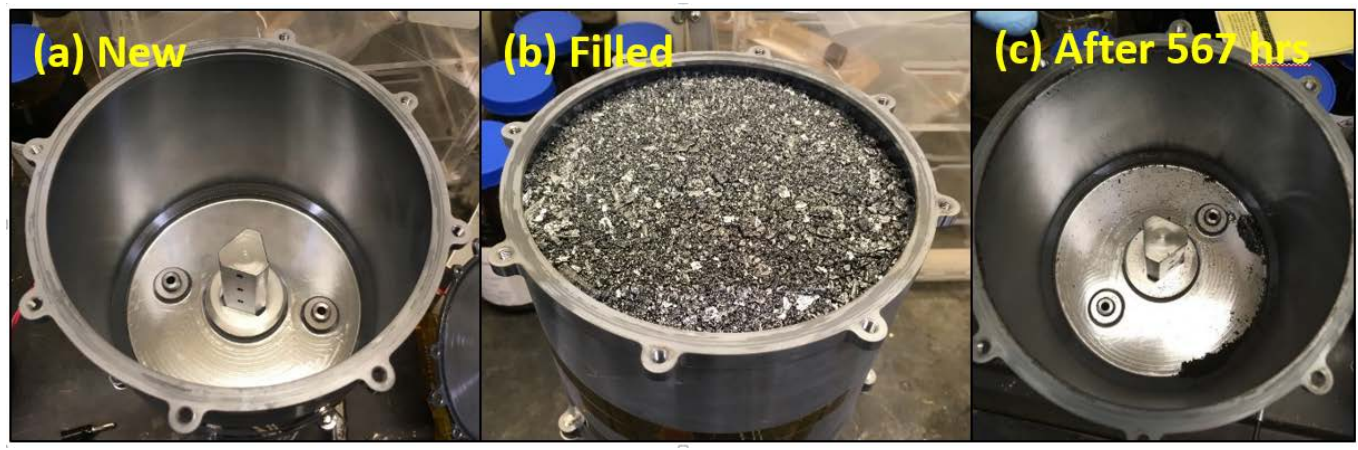

Figure 13: Iodine storage tank used in propulsion system demonstration (a) new prior to iodine loading, (b) after first filling with $5 \mathrm{~kg}$, and (c) after 567 hours of operation.

Table 1: Thruster xenon periodic performance measurements at $200 \mathrm{~V}, 250 \mathrm{~V}$, and $300 \mathrm{~V}$.

\begin{tabular}{|c|c|c|c|c|c|c|c|c|c|c|c|c|c|c|c|}
\hline \multicolumn{2}{|c|}{ Xenon Data } & \multicolumn{4}{|c|}{$200 \mathrm{~V}$} & \multicolumn{4}{|c|}{$250 \mathrm{~V}$} & \multicolumn{6}{|c|}{$300 \mathrm{~V}$} \\
\hline Variable & [Unit] & $0 \mathrm{hrs}$ & $569 \mathrm{hrs}$ & 705 hrs & $\begin{array}{c}1,174 \\
\text { hrs }\end{array}$ & $0 \mathrm{hrs}$ & $569 \mathrm{hrs}$ & $705 \mathrm{hrs}$ & $\begin{array}{c}1,174 \\
\text { hrs }\end{array}$ & $0 \mathrm{hrs}$ & $307 \mathrm{hrs}$ & *567 & $\begin{array}{c}* * 567 \\
\text { hrs }\end{array}$ & $\begin{array}{c}{ }^{*} 705 \\
\text { hrs }\end{array}$ & $\begin{array}{c}1,174 \\
\text { hrs }\end{array}$ \\
\hline$I_{d}$ & [A] & 2.01 & 2.20 & 2.05 & 2.00 & 2.01 & 2.16 & 2.00 & 2.01 & 2.01 & 2.03 & 2.05 & 2.00 & 2.01 & 2.01 \\
\hline Xe, Anode & {$[\mathrm{mg} / \mathrm{s}]$} & 2.59 & 2.59 & 2.40 & 2.35 & 2.54 & 2.54 & 2.33 & 2.32 & 2.52 & 2.52 & 2.52 & 2.41 & 2.34 & 2.30 \\
\hline Xe, Cathode & {$[\mathrm{mg} / \mathrm{s}]$} & 0.2 & 0.2 & 0.2 & 0.2 & 0.2 & 0.2 & 0.2 & 0.2 & 0.2 & 0.2 & 0.2 & 0.2 & 0.2 & 0.2 \\
\hline Thrust & {$[\mathrm{mN}]$} & 31.4 & 29.1 & 28.1 & 28.4 & 37 & 34.3 & 31.3 & 31.7 & 41.3 & 39.4 & 38.2 & 36.4 & 35.1 & 34.8 \\
\hline$v_{k}$ & [V] & 15.0 & 15.1 & 15.1 & 14.9 & 14.0 & 16 & 15.3 & 15.0 & 14.3 & 14.7 & 14.8 & 15.0 & 15.2 & 14.9 \\
\hline$v_{c-g}$ & [V] & -15.7 & -13.5 & -13.9 & -13.4 & -16.1 & -14.6 & -13.2 & -13.1 & -16.1 & -14.2 & -14.0 & -14.1 & -13.7 & -13.5 \\
\hline$I_{d} P-P$ & [A] & 2.48 & 3.92 & 2.56 & 2.00 & 2.52 & 4.32 & 3.28 & 4.48 & 2.68 & 3.00 & 1.20 & 4.44 & 4.00 & 3.36 \\
\hline$I_{d}$ RMS & [A] & 2.10 & 2.35 & 2.10 & 2.26 & 2.12 & 2.33 & 1.92 & 2.36 & 2.13 & 2.17 & 2.26 & 2.27 & 2.24 & 2.08 \\
\hline Isp & {$[s]$} & 1147 & 1063 & 1102 & 1135 & 1377 & 1276 & 1261 & 1282 & 1548 & 1477 & 1432 & 1422 & 1409 & 1419 \\
\hline Thrust/Pwr & {$[\mathrm{mN} / \mathrm{kW}]$} & 78.1 & 66.1 & 68.5 & 71.0 & 73.6 & 63.5 & 62.6 & 63.1 & 68.5 & 64.7 & 62.1 & 60.7 & 58.2 & 57.7 \\
\hline
\end{tabular}

*Before Event, **After Event

Following establishment of the xenon performance baseline, the cathode was maintained at $0.2 \mathrm{mg} / \mathrm{s}$ xenon and the iodine tank temperature was slowly raised until a discharge current of $2 \mathrm{~A}$ was achieved at $300 \mathrm{~V}$. The storage tank temperature was slowly adjusted over the duration of the demonstration as required to maintain a discharge current of $2 \mathrm{~A}$ at $300 \mathrm{~V}$. Discharge current was nearly always maintained between 1.97 and 2.03 amps over the duration of the demonstration with only slight manual temperature adjustments every 8-12 hours. Finer discharge current control could have been achieved by instituting a closed-loop temperature control, but man-in-the-loop was deemed most appropriate for this demonstration given initial uncertainties regarding the systems operational characteristics. For comparison, select performance data on iodine taken at times similar to the xenon performance map is presented in Table 2. Iodine mass flow rate is estimated based on the average iodine exhausted for each tank load. The iodine mass flow rate at 540 and 569 hours is estimated as the average over the entire 1174-hour test. As such, the specific impulses presented in Table 2 are only estimates. However, the thrust and estimated specific impulses for both iodine and xenon track well throughout the demonstration.

Figure 14 is a photograph of the BHT-600-I operating at 300V, 2A on iodine in GRC VF7 at approximately 600hours. For a more thorough comparison of the BHT-600-I on both iodine and xenon throughout the demonstration, the thrust-to-power ratio $(\mathrm{mN} / \mathrm{kW})$ is plotted in Figure 15. Again note that iodine and xenon performance tracked well throughout the demonstration, each showing an approximate $16 \%$ reduction in thrust-to-power over 1,174-hours. The test demonstrates that from a purely thruster performance perspective iodine is nearly a one-to-one replacement for xenon in Hall-effect thrusters.

Although the overall demonstration of an iodine electric propulsion system was quite successful, there were a number of challenges throughout the 1,174-hour demonstration. A timeline of events is provided in Table 3. Most notably, on 21 August 2017 an uncontrolled purge of iodine from VF7 occurred. Following a liquid nitrogen (LN2) delivery, a vent valve was not properly resealed by the contractor resulting in an eventual loss of the LN2 tank pressure. Without sufficient tank head pressure, LN2 ceased being delivered to the vacuum facility, resulting in a loss of iodine containment on the LN2 chevrons. Heat from the ODPs sublimated the iodine, which exhausted into the primary roughing train, became trapped in the roughing pump oil, and in part vented to the facility roof. While the LN2 system failure did not endanger the experiment or personnel, significant vacuum facility iodine contamination occurred, 
requiring approximately one month to sufficiently remediate before testing could resume. Should future iodine work be performed in VF7, facility modifications are recommended to prevent such a future occurrence.

Table 2: Thruster iodine performance measurements at $300 \mathrm{~V}$. Iodine mass flow rates and specific impulses estimated based on average iodine exhausted over the demonstration.

\begin{tabular}{|l|c|c|c|c|c|c|c|c|}
\hline \multicolumn{2}{|c|}{ lodine Data } & \multicolumn{7}{|c|}{$300 \mathrm{~V}$} \\
\hline Variable & {$[$ Unit] } & 1 hrs & $308 \mathrm{hrs}$ & $\begin{array}{c}* 540 \\
\text { hrs }\end{array}$ & $* * 569$ & $\begin{array}{c}* 705 \\
\text { hrs }\end{array}$ & $* * 705$ & $\begin{array}{c}1,144 \\
\text { hrs }\end{array}$ \\
\hline$I_{d}$ & {$[\mathrm{~A}]$} & 2.06 & 2.02 & 1.98 & 1.94 & 1.99 & 2.00 & 2.00 \\
\hline $\mathrm{I}_{2}$, Estimate & {$[\mathrm{mg} / \mathrm{s}]$} & \multicolumn{2}{|c|}{2.47} & \multicolumn{2}{|c|}{2.38} & \multicolumn{3}{c|}{2.29} \\
\hline Xe, Cathode & {$[\mathrm{mg} / \mathrm{s}]$} & 0.2 & 0.2 & 0.2 & 0.2 & 0.2 & 0.2 & 0.2 \\
\hline Thrust & {$[\mathrm{mN}]$} & 40.7 & 38.2 & 34.7 & 33.9 & 34 & 34.6 & 33.5 \\
\hline$V_{k}$ & {$[\mathrm{~V}]$} & 14 & 13.9 & 14.6 & 15.2 & 14.6 & 15.0 & 15.1 \\
\hline $\mathrm{V}_{\text {c-g }}$ & {$[\mathrm{V}]$} & -16.8 & -14.8 & -14.0 & -14.3 & -14.1 & -14.6 & -14.4 \\
\hline $\mathrm{I}_{\mathrm{d}}$ P-P & {$[\mathrm{A}]$} & 1.6 & 2.60 & 1.2 & 2.96 & 2.80 & 1.82 & 2.56 \\
\hline $\mathrm{I}_{\mathrm{d}}$ RMS & {$[\mathrm{A}]$} & 2.09 & 2.25 & 2.11 & 2.16 & 2.16 & 2.09 & 2.00 \\
\hline Isp, Estimate & {$[\mathrm{s}]$} & 1554 & 1458 & 1371 & 1339 & 1392 & 1416 & 1371 \\
\hline Thrust/Pwr & {$[\mathrm{mN} / \mathrm{kW}]$} & 65.9 & 63.0 & 58.4 & 58.2 & 57.0 & 57.7 & 55.8 \\
\hline
\end{tabular}

*Before Event, **After Event

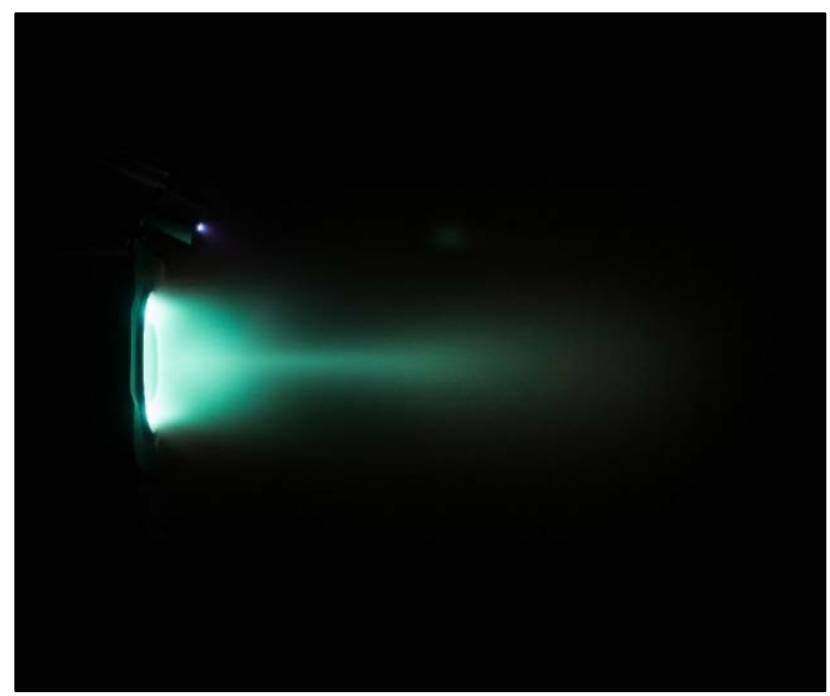

Figure 14: BHT-600-I operating on iodine matched with a GRC cathode operating on xenon in GRC VF7.

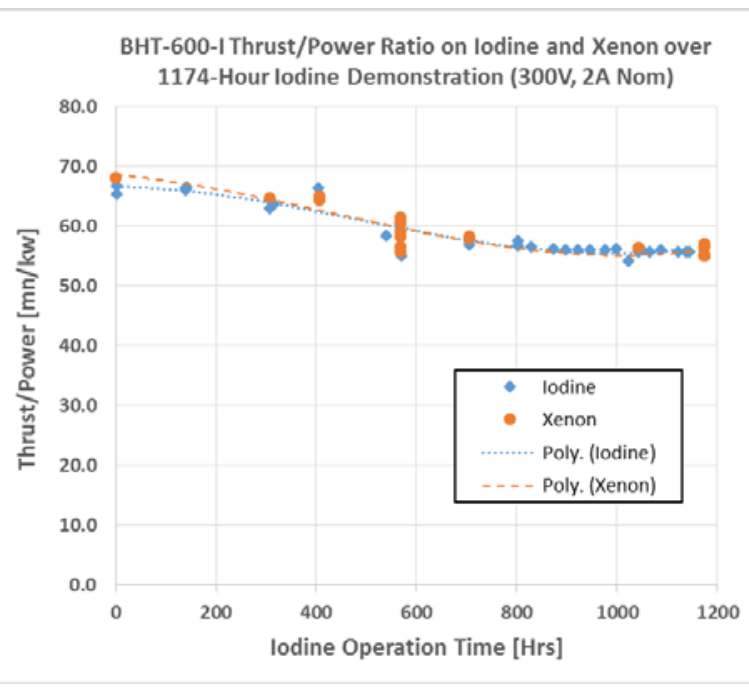

Figure 15: BHT-600-I thrust to power ratio for iodine and xenon over 1,174-hour iodine demo.

Also, on 2 October 2017, the propulsion system ceased functioning while operating on iodine. An attempt to restart the propulsion system on xenon was unsuccessful. The propulsion system was behaving in a manner characteristic with an electrical short. The chamber was decontaminated and vented to access the experiment and assess the issue. It was determined that a non-iodine compatible ring-terminal internal to the BHT-600-I was employed to attach the anode power line during thruster assembly. The failure of such a minor component aptly illustrates the vigilance that will be required for production of highly reliable iodine resistant spaceflight hardware. The thruster manufacturer was consulted, a repair plan was developed, and the ring-terminal was successfully replaced without removing the propulsion system from the test stand.

While repairing the anode power ring-terminal, physical inspection of the test article noted that alloying elements were being leached from the thruster body material, most specifically thruster body internal surfaces exposed to high temperature during thruster operation. The issue did not present a complication during the thruster demonstration, but selection of alternate materials for these components are desirable for future iodine-resistant thruster iterations.

The demonstration was completed on 18 November 2017 when the second load of iodine was exhausted. Up until the last of the iodine was exhausted, operation of the propulsion system was stable and reliable. The primary goal to demonstrate greater than 1,000-hours of propulsion system operation on iodine was achieved, although a fill operation and minor repair operation were required. While there was no attempt made to collect data necessary to estimate the 
lifetime of the propulsion system on iodine, no difficulties existed at the conclusion of the test that would have prevented further testing had it been decided to continue. At this time, there is no strong indications to believe the lifetime of the thruster with iodine should necessarily be different than with xenon assuming some minor improvements in body material iodine-compatibility can be implemented.

Table 3: Timeline of events for 1,174-hour iodine propulsion system demonstration.

\begin{tabular}{|c|c|c|c|c|}
\hline \# & Date & Event & $\mathbf{I}_{2} \mathbf{H r s}$ & Comments \\
\hline 1 & 06/29/17 & Load iodine & --- & $5.037 \mathrm{~kg}$ iodine loaded \\
\hline 2 & $07 / 25 / 17$ & Demonstration initiated & 0 & Baseline on xenon; initiated iodine demonstration \\
\hline 3 & $08 / 07 / 17$ & Thrust stand calibration & 307 & Assess performance with xenon at $300 \mathrm{~V}$ \\
\hline 4 & $08 / 11 / 17$ & Discharge over-current & 405 & Auto-shutdown; Cause unknown; Assess performance xenon \\
\hline 5 & $08 / 17 / 17$ & Thrust stand calibration & 540 & \\
\hline 6 & $08 / 18 / 17$ & Thruster shutdown & 567 & Iodine exhausted \\
\hline 7 & $08 / 21 / 17$ & Thruster checkout & 567 & Assess performance with xenon \\
\hline 8 & $08 / 21 / 17$ & LN2 failure & 567 & Uncontrolled vent of iodine \\
\hline 9 & $09 / 01 / 17$ & Thruster checkout & 567 & Assess performance with xenon \\
\hline 10 & $09 / 07 / 17$ & Vent chamber & 567 & Vent and decontaminate to access experiment \\
\hline 11 & 09/20/17 & Load iodine & 567 & $4.996 \mathrm{~kg}$ iodine loaded \\
\hline 12 & $09 / 25 / 17$ & Thruster checkout & 567 & Assess performance with xenon \\
\hline 13 & $09 / 26 / 17$ & Demonstration resumed & 567 & Checkout on xenon; resumed iodine demonstration \\
\hline 14 & $10 / 02 / 17$ & Discharge over-current & 705 & Auto-shutdown; Unable to restart \\
\hline 15 & $10 / 03 / 17$ & Vent chamber & 705 & Vent and decontaminate to access experiment \\
\hline 16 & $10 / 18 / 17$ & Diagnose thruster & 705 & Anode power line failed at anode termination \\
\hline 17 & $10 / 23 / 17$ & Repair & 705 & Replaced anode power line termination \\
\hline 18 & $10 / 30 / 17$ & Demonstration resumed & 705 & Checkout on xenon; resumed iodine demonstration \\
\hline 19 & $11 / 03 / 17$ & Thrust stand calibration & 802 & Calibrate thrust stand; resumed iodine demonstration \\
\hline 20 & $11 / 13 / 17$ & Thrust stand calibration & 1044 & Calibrate thrust stand; resumed iodine demonstration \\
\hline 21 & $11 / 18 / 17$ & Thruster shutdown & 1174 & Iodine exhausted; Auto-shutdown \\
\hline 22 & $11 / 20 / 17$ & Thrust stand calibration & 1174 & Assess performance with xenon \\
\hline
\end{tabular}

Figures 16 and 17 below present the power spectral density (PSD) profiles for the BHT-600-I discharge current waveforms for xenon and iodine operation, respectively, at a discharge current of $\sim 2 \mathrm{~A}$ at selected test ellapsed times. Profiles presented in Figure 16 indicate that there was a shift in the discharge dominant frequency from 35 khz to $\sim 43 \mathrm{khZ}$ after operating for 307 hours. The PSD profile at 567 hour (prior to end of segment 1) indicates another change in the PSD profile that indicates a change in the thruster's discharge characteristics (Table 1 shows a change in the Pk-Pk from $3 \mathrm{~A}$ at 307 hours to $4.44 \mathrm{~A}$ at 567 hours). The change in the profile may be attributed to changes in the discharge channel profile due to erosion and due to the degradation of the dielectric coating on the thruster's midstem, which could be causing a change in the current collected by the thruster. The test was then halted to reload iodine. After restarting the test, the measured PSD profile indicates a profile that is different than prior to halting the test. This could be attributed to the fact that the facility background pressure was slightly higher during the second test segment. The PSD profiles at 567, 705, and 1,174 hours are very similar; it is speculated that the slight change in the discharge current waveform over the second segment may be an indication that the discharge channel profile may have progressed to a profile that is close to its EOL profile and as such no significant further changes in the discharge waveform were occuring.

Figure 17 presents the discharge current PSDs for iodine propellant operation. The trends presented in Figure 17 are very similar to the ones presented in Figure 16. In segment 1, noticeable changes occurred in the discharge current waveform profiles (dominant frequency, Pk-Pk, and RMS) but in segment 2 the changes were much less noticable.

Figures 18, 19, and 20 present a comparison between discharge current PSDs for xenon and iodine operation at beginning of test (BOT), 567, and end of test (EOT), respectively. The Figures indicate that, in general, the discharge 
current $\mathrm{Pk}-\mathrm{Pk}$ is lower for iodine operation when compared to xenon, and that the variation of the PSD profiles with time is similar for xenon and iodine propellants.

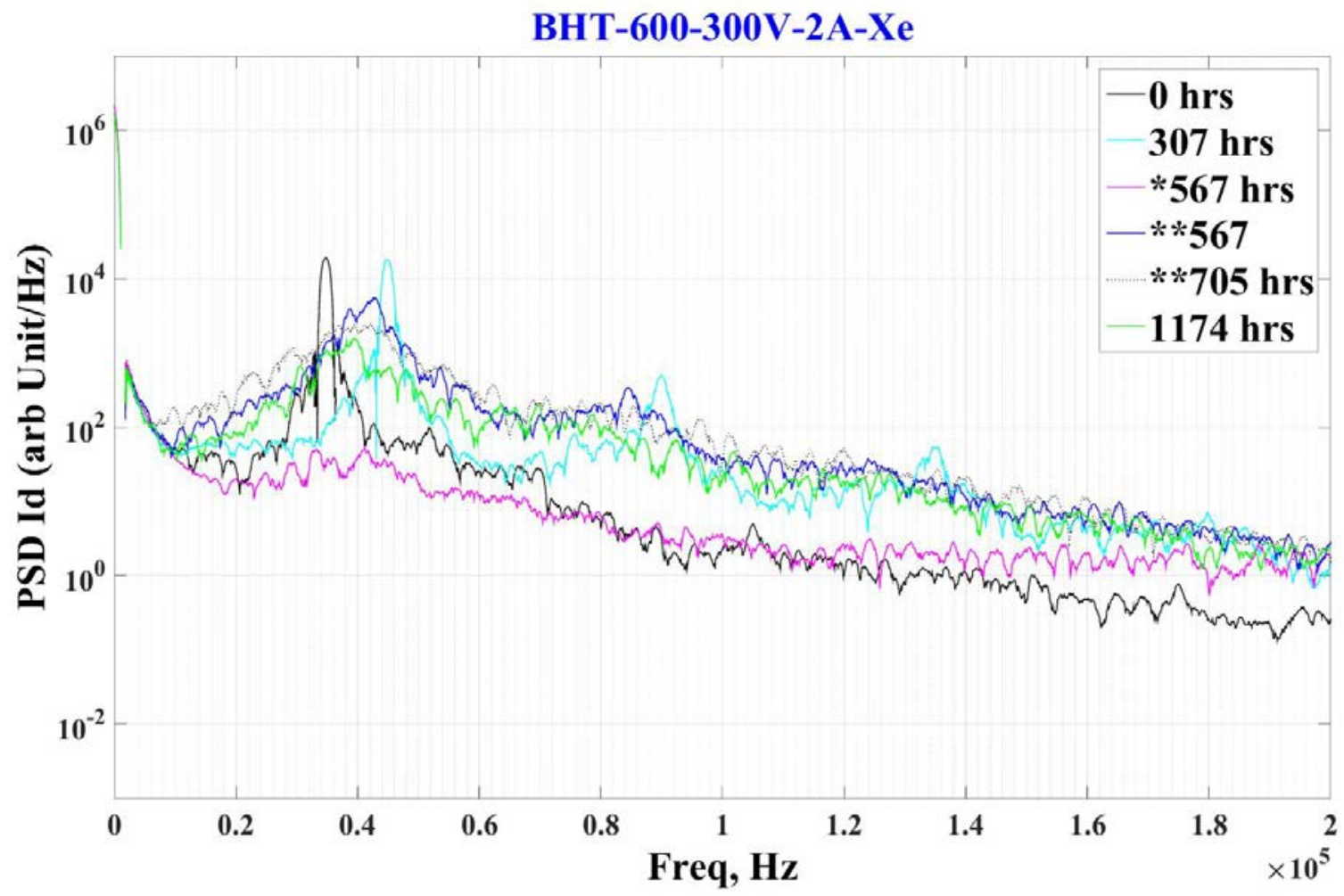

Figure 16: BHT-600-I discharge current waveform PSDs for xenon propellant operation.

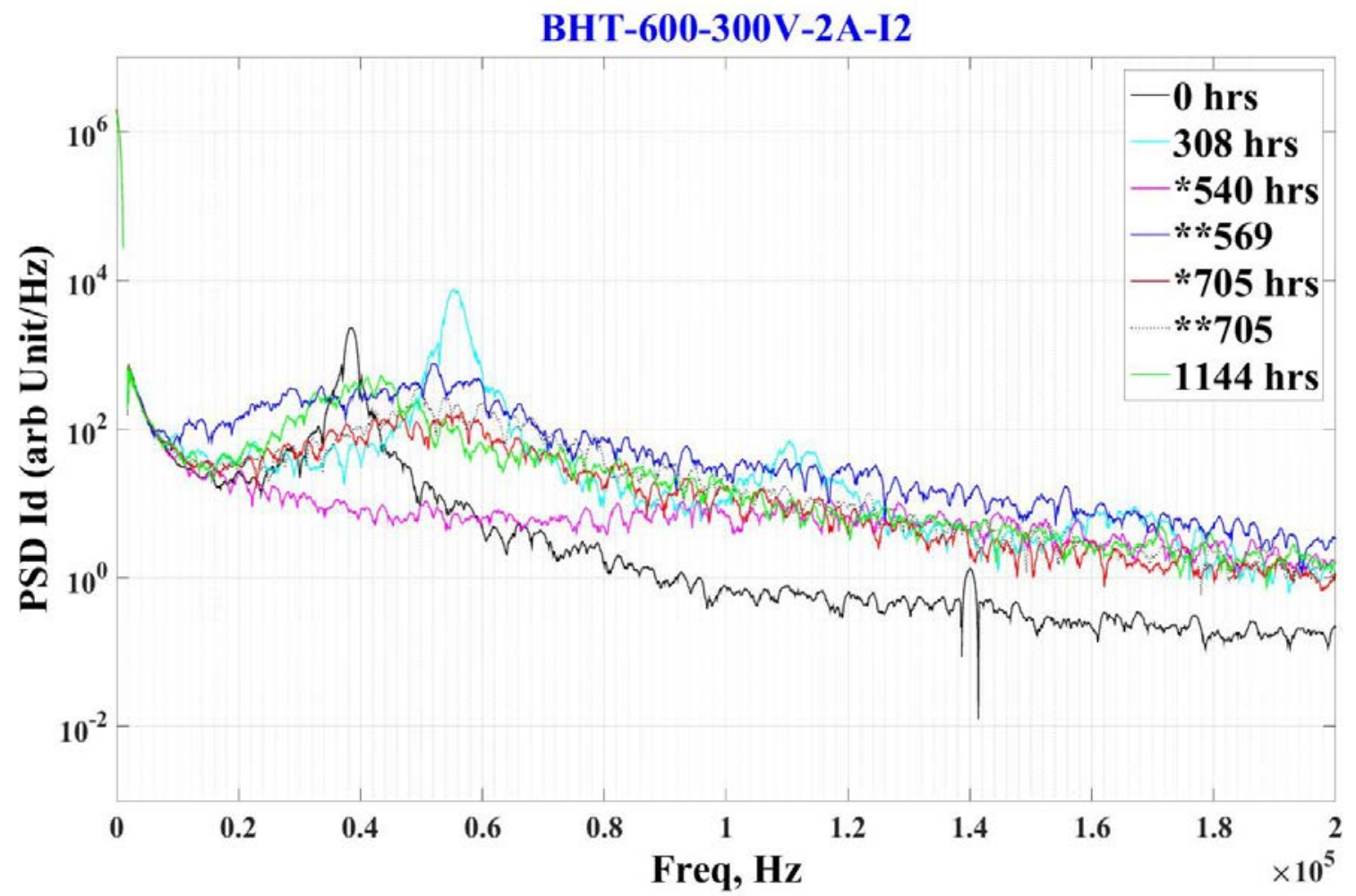

Figure 17: BHT-600-I discharge current waveform PSDs for iodine propellant operation. 


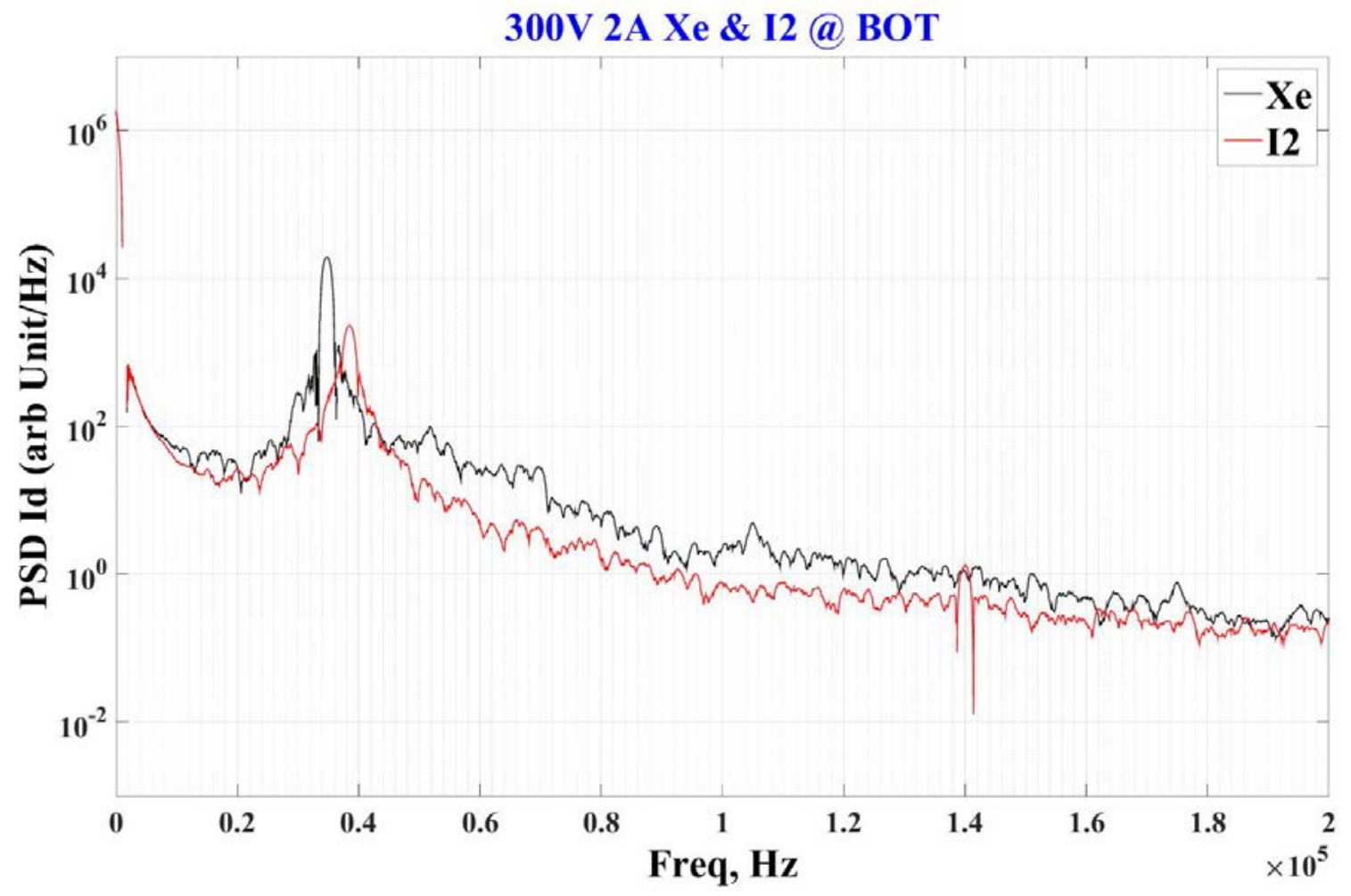

Figure 18: BHT-600-I discharge current waveform PSDs for xenon and iodine at BOT.

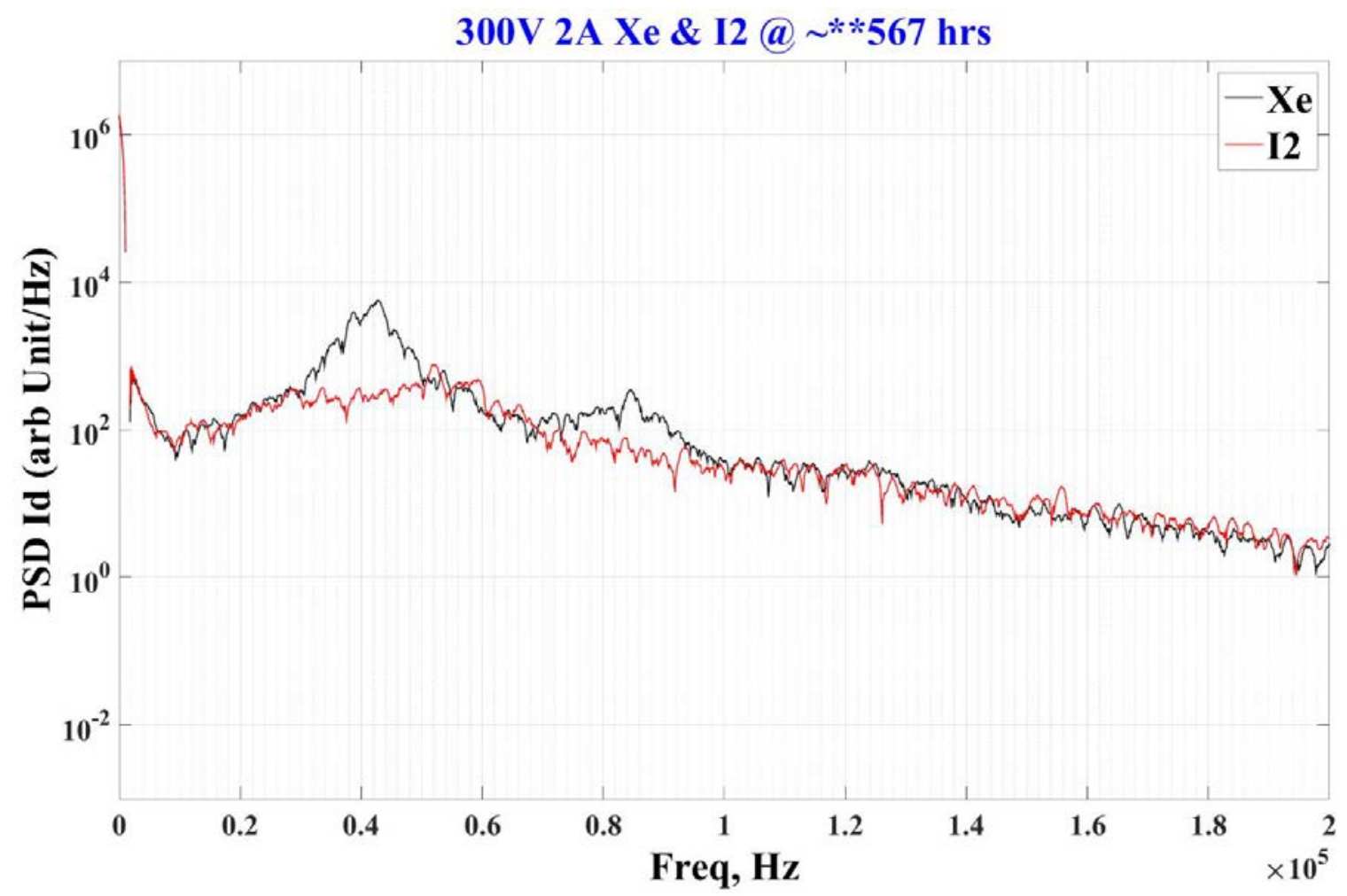

Figure 19: BHT-600-I discharge current waveform PSDs for xenon and iodine at 567 hours. 


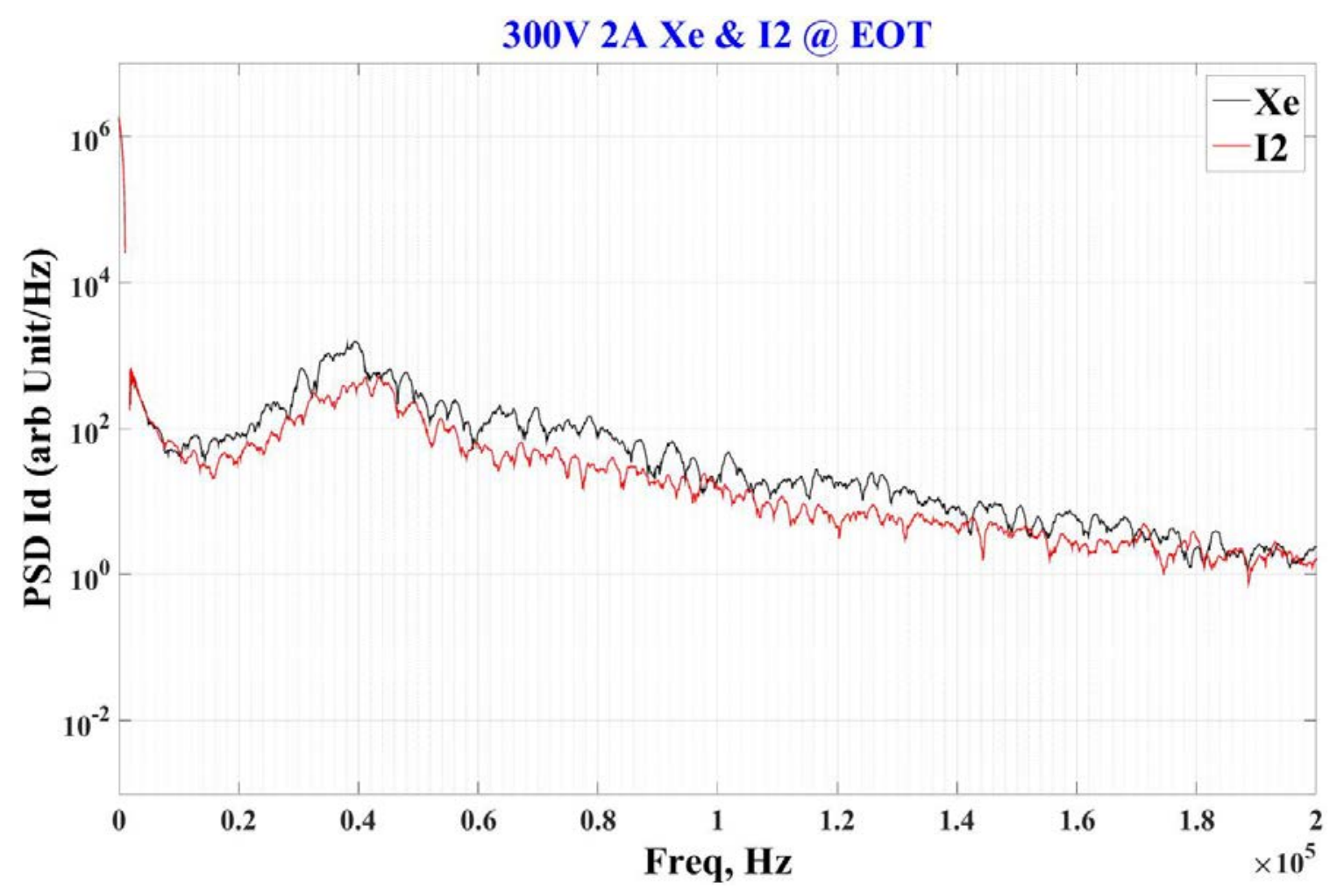

Figure 20: BHT-600-I discharge current waveform PSDs for xenon and iodine at 1,174 hours (EOT).

\section{Summary and Conclusions}

This paper reviewed recent iodine-compatible electric propulsion research and development conducted at the NASA Glenn Research Center. The work included (i) investigation of the iodine compatibility of $\mathrm{BaO}-\mathrm{CaO}-\mathrm{Al}_{2} \mathrm{O}_{3}$ impregnated tungsten hollow cathodes based on a flight heritage design, (ii) investigation of the iodine compatibility of a handful of materials common to propulsion systems, spacecraft, and ground test facilities, (iii) development of reliable iodine feed system technologies, (iv) implementation of test facility improvements in an attempt to mitigate iodine associated negative impacts, and culminated in (v) an 1,174-hour hybrid iodine-xenon propulsion system durability demonstration (iodine fed Hall-effect thruster with xenon fed cathode).

The demonstration employed a Busek BHT-600-I Hall-effect thruster, a GRC BaO hollow cathode, and a GRC iodine feed system. The propulsion system was operated using laboratory power supplies. While the initial intent was to operate the propulsion system all-iodine to minimize system complexity, a sufficiently iodine compatible cathode could not be identified, and as a result the system was operated in a hybrid iodine-xenon configuration. For a nearterm flight demonstration, a hybrid feed system would still achieve a significant reduction in the propellant tank volume compared to an all-xenon system, since the cathode flow rate is typically on the order of $7 \%$ that of the total propellant mass flow, but avoid the known iodine-compatible cathode development challenges. The test demonstrated:

(i) a Hall effect thruster operates with similar performance whether employing iodine or xenon propellant over long-duration;

(ii) careful selection of propulsion system materials and coatings can result in durable iodine-compatible hardware; and

(iii) implementation of appropriate facility improvements and procedures can limit negative impacts of iodine on test hardware and ground support equipment, although facility challenges with iodine are extensive.

Although some inadequacies of the experimental hardware and test facilities were revealed through a loss of iodine containment at 567-hours and an electrical connection failure at 705-hours, demonstration of 1,174 total hours of operation verify that implementation of iodine as a propellant in electric propulsion devices is feasible, although challenging. A lack of contamination or degradation of the xenon-fed cathode assembly in proximity to the iodine-fed thruster is very encouraging as an interim solution until sufficiently iodine compatible cathodes are developed. Use of 
coating such as silicon, as demonstrated in the laboratory iodine feed system, may also provide direction for low-cost methods to improve iodine compatibility of spacecraft subsystems. Nonetheless, as encouraging as the demonstration's results, it is also clear that much work remains in further refining iodine propulsion system technologies, constructing dedicated iodine compatible test facilities, and better understanding the potential long-term impacts of iodine plumes on spacecraft systems and payloads.

\section{Acknowledgments}

The authors wish to thank James Schneider and Richard Polak for the exceptional work preparing and maintaining the vacuum facilities given the additional rigors required due to the iodine propellant. We would also like to thank the Game Changing Development (GCD) program within NASA's Science Technology Mission Directorate (STMD) for recognizing NASA's need to stay on the forefront of in-space propulsion technologies and supporting these important technology demonstrations.

\section{References}

[1] Roy, S. A., “The origin of the smaller, faster, cheaper approach in NASA's solar system exploration program,” Space Policy, volume 14, issue 3, 1998, p152-171.

[2] Small Spacecraft Technology State of the Art, Mission Design Division, Ames Research Center, Moffett Field, CA, 2015

[3] Karuntzos, K., “United Launch Alliance Rideshare Capabilities for Providing Low-Cost Access to Space,” IEEE, Big Sky, MT, 2015.

[4] Alvarez, J., “Constellations, Clusters, and Communication Technology: Expanding Small Satellite Access to Space,” IEEE, Big Sky, MT, 2016.

[5] Maly, J. R. and Stender, M., “Moog Capabilities for Small Satellites,” $13^{\text {th }}$ Annual CubeSat Developer’s Workshop, San Luis Obispo, CA, 2016.

[6] Szabo, J., Pote, B., Paintal, S., Robin, M., Kolencik, G, Hillier, A., Branam, R. D., and Huffman, R. E., "Performance Evaluation of an Iodine Vapor Hall Thruster," 47 th AIAA/ASME/SAE/ASEE Joint Propulsion Conference, San Diego, CA, 2011.

[7] Szabo, J., Robin, M., Paintal, S., Pote, B., Hruby, V., and Freeman, C., “Iodine Propellant Space Propulsion,” International Electric Propulsion Conference, Washington D.C., 2013.

[8] Tsay, M., Frongillo, J., Model, J., Zwahlen, J., and Paritsky, L., "Maturation of Iodine-Fueled BIT-3 RF Ion Thruster and RF Neutralizer,” 52 ${ }^{\text {nd }}$ AIAA/SAE/ASEE Joint Propulsion Conference, Salt Lake City, UT, 2016.

[9] Maly, J. R., Sandord, G. E., Williams, A., and Berenberg, L., "ESPA Class Redefined, $31^{\text {st }}$ Annual AIAA/USU Conference on Small Satellites,” Logan, UT, 2017.

[10] Jehle, A., "Iodine Small Satellite Propulsion Demonstration - iSAT,” 31 ${ }^{\text {st }}$ AIAA/USU Conference on Small satellites, Logan, UT, 2017.

[11] Costa, G. C. C., Benavides, G. F., and Smith, T. D., "Chemical, Structural, and Microstructural Changes in Metallic and Silicon-Based Coating Materials Exposed to Iodine Vapor,” NASA/TM-2017-219498.

[12] Wren, J. C., Glowa, G. A., Merritt, J. “Corrosion of Stainless Steel by Gaseous I2,” Journal of Nuclear Materials, 265, 161177, (199).

[13] Lide, D. R., CRC Handbook of Chemistry and Physics, 71st Ed., CRC Press, Boca Raton, FL, (1990).

[14] Donchev, A., Gleeson, B., Shütze, M., "Thermodynamic Considerations of the Beneficial Effect of Halogens on the Oxidation Resistance of TiAl-based Alloys,” Intermetallics, 11, 387-398, 2003.

[15] Tredmon, C. S., “The Effect of Oxide Volatilization on the Oxidation Kinetics of Cr and Fe-Cr Alloy,” Journal of the Electrochemical Society, 113, 766-768, (1966).

[16] Maloney, M. J., and Mcnallan, M. J., "The Effect of Chlorine on the Kinetics of Oxidation of Colbalt in Environments Containing 0.5 Atmosphere of Oxygen between 900 K and 1200 K,” Metallurgical transactions B, 16, 751-761, (1985). 